\title{
Macrophages of multiple sclerosis patients display deficient SHP-1 expression and enhanced inflammatory phenotype
}

\author{
George P Christophi ${ }^{1,2}$, Michael Panos ${ }^{1,2}$, Chad A Hudson ${ }^{1,2}$, Rebecca L Christophi ${ }^{1,2}$, Ross C Gruber ${ }^{1,2}$, \\ Akos T Mersich $^{3}$, Scott D Blystone ${ }^{3}$, Burk Jubelt ${ }^{1,2}$ and Paul T Massa ${ }^{1,2}$
}

Recent studies in mice have demonstrated that the protein tyrosine phosphatase SHP-1 is a crucial negative regulator of proinflammatory cytokine signaling, TLR signaling, and inflammatory gene expression. Furthermore, mice genetically lacking SHP-1 (me/me) display a profound susceptibility to inflammatory CNS demyelination relative to wild-type mice. In particular, SHP-1 deficiency may act predominantly in inflammatory macrophages to increase CNS demyelination as SHP1-deficient macrophages display coexpression of inflammatory effector molecules and increased demyelinating activity in $\mathrm{me} / \mathrm{me}$ mice. Recently, we reported that PBMCs of multiple sclerosis (MS) patients have a deficiency in SHP-1 expression relative to normal control subjects indicating that SHP-1 deficiency may play a similar role in MS as to that seen in mice. Therefore, it became essential to examine the specific expression and function of SHP-1 in macrophages from MS patients. Herein, we document that macrophages of MS patients have deficient SHP-1 protein and mRNA expression relative to those of normal control subjects. To examine functional consequences of the lower SHP-1, the activation of STAT6, STAT1, and NF- $\kappa$ B was quantified and macrophages of MS patients showed increased activation of these transcription factors. In accordance with this observation, several STAT6-, STAT1-, and NF- $\kappa$ B-responsive genes that mediate inflammatory demyelination were increased in macrophages of MS patients following cytokine and TLR agonist stimulation. Supporting a direct role of SHP-1 deficiency in altered macrophage function, experimental depletion of SHP-1 in normal subject macrophages resulted in an increased STAT/NF- $\kappa$ B activation and increased inflammatory gene expression to levels seen in macrophages of MS patients. In conclusion, macrophages of MS patients display a deficiency of SHP-1 expression, heightened activation of STAT6, STAT1, and NF- $\kappa$ B and a corresponding inflammatory profile that may be important in controlling macrophage-mediated demyelination in MS.

Laboratory Investigation (2009) 89, 742-759; doi:10.1038/labinvest.2009.32; published online 27 April 2009

KEYWORDS: human; macrophages; cytokines; transcription factors; inflammation; autoimmunity/multiple sclerosis

Multiple sclerosis is a chronic inflammatory demyelinating disease of the central nervous system (CNS) that remains a major cause of disability. ${ }^{1}$ Several studies demonstrated that MS lesions contain multiple leukocyte cell types including lymphocytes, macrophages, and dendritic cells all of which are believed to contribute to lesion formation by various distinct and interacting mechanisms. ${ }^{2,3}$ Among these leukocyte subsets, infiltrating macrophages have been identified as major effectors of demyelination in both MS and animal models for MS. ${ }^{4-11}$ In accord with these studies, it was re- cently described that a predominant mechanism of demyelination in MS is macrophage mediated. ${ }^{12}$

These findings have stimulated intense interest on the various effector functions of macrophages in lesion formation including signaling events that draw these cells into the CNS white matter and trigger the effector mechanisms by which these cells destroy myelin. For instance, macrophages have been identified as the major responders to CNS chemokines, producers of a number of proinflammatory cytokines, chemokines, and toxic molecules known to

\footnotetext{
'Department of Neurology, SUNY Upstate Medical University, Syracuse, NY, USA; ${ }^{2}$ Department of Microbiology and Immunology, SUNY Upstate Medical University, Syracuse, NY, USA and ${ }^{3}$ Department of Cell and Developmental Biology, SUNY Upstate Medical University, Syracuse, NY, USA

Correspondence: Dr PT Massa, PhD, Department of Neurology, Upstate Medical University, State University of New York, 750 East Adams Street, Syracuse, NY 13210, USA. E-mail: massap@upstate.edu

Received 8 February 2009; revised 12 March 2009; accepted 14 March 2009
} 
promote demyelination, ${ }^{7,13-18}$ and the major cells involved in phagocytosis/degradation of myelin sheathes. Interestingly, both leukocytes and CNS plaques of MS patients contain activated transcription factors such as NF- $\kappa \mathrm{B},{ }^{19,20}$ STAT $1,{ }^{20-22}$ and STAT6, ${ }^{23-25}$ which can lead to enhanced expression of these inflammatory effector functions in macrophages. Based on our previous work, we propose that modulation of inflammatory signaling via these multiple transcriptional pathways may be deficient in leukocytes, including inflammatory macrophages of MS patients, and that this deficiency is responsible for susceptibility to inflammatory demyelinating processes within the CNS.

SHP-1 is a protein tyrosine phosphatase with two $\mathrm{SH} 2$ domains which acts as a negative regulator of both innate and acquired immune cytokine signaling via $\mathrm{NF}-\kappa \mathrm{B},{ }^{26-28}$ STAT $1,{ }^{29,30}$ and STAT6. ${ }^{31-34}$ Mice genetically lacking SHP-1 (motheaten mice) display myelin deficiency, which may be mediated by increased innate inflammatory mediators in the CNS. ${ }^{35,36}$ Furthermore, motheaten mice are highly susceptible to experimentally induced demyelinating disease. ${ }^{37-39}$ Taken together, these studies indicate that SHP-1 is a key regulator of inflammation in the CNS that may be relevant to the pathogenesis of MS. Indeed, others and we reported that SHP-1 expression and function is deficient in leukocytes of MS patients compared to normal human subjects. ${ }^{22,25}$

We have shown that SHP-1-deficient mice uniquely display an unusually rapid CNS demyelination associated with extensive white matter cellular infiltration and clinical paralysis within the first week of Theiler's murine encephalomyelitis virus (TMEV) infection compared to their wild-type littermates. ${ }^{37}$ Recently, we have shown that SHP-1-deficient mice show a profound and predominant infiltration of blood-derived macrophages into the CNS following TMEV infection and that these macrophages are concentrated to areas of demyelination. ${ }^{9}$ Importantly, these macrophages possessed an inflammatory profile in vivo with an unusual coactivation of STAT6, STAT1, and NF- $\kappa$ B and corresponding responsive proinflammatory genes. Because of the rapidity of demyelination in this model, we proposed that SHP-1-deficient macrophages possess a particularly pronounced demyelinating phenotype. Accordingly, macrophage/monocyte depletion with clodronate liposomes resulted in a significant delay in the onset of clinical symptoms and decreased inflammation and demyelination in the spinal cords of SHP-1-deficient mice. Those studies suggested that SHP-1 is an important regulator of CNS inflammatory demyelination acting predominantly to control recruitment of macrophages into the CNS and a broad modulation of macrophage inflammatory effector functions.

In the light of recent studies demonstrating the importance of macrophages in mediating demyelination in $\mathrm{MS}^{12}$ and our recent studies in SHP-1-deficient mice cited above, ${ }^{9}$ it became imperative to characterize the inflammatory profile of macrophages of MS patients compared to normal subjects. This study demonstrates that the expression of SHP-1 is deficient in macrophages of MS patients compared to normal subjects. Corresponding with this deficiency, we show that phosphorylation of STAT6 and STAT1 and activation of NF$\kappa \mathrm{B}$ are higher in macrophages of MS patients compared to those of normal subjects. In accordance with this activation, several STAT6-, STAT1-, and NF- $\kappa$ B-responsive genes that are important for inflammatory demyelination were increased in macrophages of MS patients following cytokine stimulation. Supporting a direct role of SHP-1 deficiency in altered macrophage function, experimental depletion of SHP-1 in macrophages of normal human subjects using siRNA resulted in an increased activation of the above transcription factors and increased inflammatory gene expression to levels seen in macrophages of MS patients. Taken together, we propose the potential involvement of SHP-1 deficiency in mediating the augmented inflammatory profile in macrophages seen in MS patients and contributing to the pathogenesis of MS.

\section{MATERIALS AND METHODS Patient Selection}

Patients were clinically diagnosed for multiple sclerosis in the SUNY Upstate Medical University MS clinic by established criteria. ${ }^{40}$ Those patients were selected who had not received any disease modifying treatment such as IFN- $\beta$, glatiramir acetate, steroids, or other immunosuppressive agents at least 3 months before donating blood. In this study, macrophage cultures were obtained from 27 patients with relapsing remitting (RR) MS (mean EDSS score of $3.6+1.6$ ) and 24 normal control subjects. The patients and control normal subjects were matched in both age and gender, and the biometric data of the subjects used in this study are shown in Table 1. The Institutional Review Board of SUNY Upstate University approved all studies and both patients and control subjects granted informed consent before providing blood.

Table 1 Biometric data of MS patients and normal subjects used in the study

\begin{tabular}{lccccc}
\hline & Number of subjects & Age (years) & Gender (female/male) & Age at onset (years) & Disease duration (years) \\
\hline Normal subjects & 24 & $39 \pm 11$ & $16 / 8$ & - & - \\
MS patients & 27 & $44 \pm 12$ & $20 / 7$ & $36 \pm 9$ & $6.8 \pm 4.0$
\end{tabular}

The data are shown in mean value \pm s.d. The clinical symptoms were measured on Kurtzke's Expanded Disability Status Scale (EDSS) at the time the blood was drawn. 


\section{Human Peripheral Blood Monocyte-Derived Macrophages}

Patients and normal subjects donated $50 \mathrm{ml}$ of blood collected in heparinized tubes. Blood was diluted 1:1 with Hank's balanced salt solution (HBSS) and overlaid onto lymphocyte separation medium (Cellgro, Herndon, VA, USA). After centrifugation, the $10 \mathrm{ml}$ of the interface containing the PBMCs was collected and washed twice with HBSS. Adherent monocytes were cultured for a week in RPMI media, 15\% fetal bovine serum, and $50 \mathrm{ng} / \mathrm{ml} \mathrm{GM-CSF}$ as previously described. ${ }^{41,42}$ Medium was replenished every 3 days and nonadherent cells were removed at the second feeding (at 6 days). For experiments, cells were cultured for an additional day in the absence of GM-CSF, washed twice with PBS and adherent cells were lysed in STAT-60 (Tel-Test, Friendswood, TX, USA) for RNA analysis or RIPA buffer ${ }^{43}$ for protein analysis. For flow cytometry, cells were detached by incubating them in $5.0 \mathrm{mM}$ EDTA for $10 \mathrm{~min}$ at $37^{\circ} \mathrm{C}$. The method consistently yielded more than 95\% pure macrophages assessed by both morphological criteria as described ${ }^{44}$ and expression of the monocyte lineage marker CD14 as determined by flow cytometric analysis.

\section{Cytokine and siRNA Treatment}

Macrophages of MS patients and normal subjects were cultured for 1 week, then GM-CSF was removed from the media. Macrophages were then treated with either $10 \mathrm{ng} / \mathrm{ml}$ TNF- $\alpha, 10 \mathrm{ng} / \mathrm{ml}$ of IL-4, $100 \mathrm{U} / \mathrm{ml}$ IFN- $\gamma$ (R\&D Systems, Minneapolis, MN, USA), $5 \mu \mathrm{g} / \mathrm{ml}$ of LPS (Salmonella minnesota re595 LPS; Sigma-Aldrich, St Louis, MO, USA), $5 \mu \mathrm{g}$ / $\mathrm{ml}$ of dsRNA (polyinosinic/polycytidylic acid; Amersham Pharmacia, Piscataway, NJ, USA) or received medium alone for $18 \mathrm{~h}$.

Anti-SHP-1 siRNA was used to deplete SHP-1 from macrophages of normal subjects. Macrophages were transfected with siRNA against human SHP-1 or scramble siRNA (Dharmacon, Chicago, IL, USA) at a concentration of $1 \mu \mathrm{g} /$ $10^{6}$ cells. The transfection reagent (Dharmafect 4; Dharmacon) was used as specified by the manufacturer. Cells were incubated in the transfection medium for $24 \mathrm{~h}$, after which the medium was replaced with complete growth medium for another $48 \mathrm{~h}$ before cytokine treatment. The effectiveness of the SHP-1 siRNA to lower SHP-1 expression was evaluated by western immunoblot.

\section{Real-Time RT-PCR}

Total RNA was isolated using RNA STAT-60. RNA was quantified spectrophotometrically and $0.5 \mu \mathrm{g}$ of total RNA was converted into cDNA. Briefly, total RNA and random primers (Invitrogen, Carlsbad, CA, USA) were incubated at $72^{\circ} \mathrm{C}$ for $10 \mathrm{~min}$. Reverse transcription was performed using the Superscript II RT enzyme (Invitrogen) and followed the specification of the manufacturer. cDNA was diluted to $200 \mu \mathrm{l}$ with water and $4 \mu \mathrm{l}$ was used for quantitative real-time PCR using SYBR Green kit (Abgene, Epson, UK). The PCR parameters were $15 \mathrm{~min}$ for $95^{\circ} \mathrm{C}$ and 35 cycles of $95^{\circ} \mathrm{C}$ for $15 \mathrm{~s}$ and $60^{\circ} \mathrm{C}$ for $1 \mathrm{~min}$ in ABI prism 700 (Applied Biosystems, Foster city, CA, USA). The primers were used at $10 \mathrm{nM}$. Serial dilutions of cDNA containing a known copy number of each gene were used in each quantitative PCR run to generate a standard curve relating copy number with threshold amplification cycle. ${ }^{45}$ Gene expression levels were calculated during the logarithmic amplification phase by determining the initial mRNA copy number using the standard curve. Amplification of each gene-specific fragment was confirmed both by examination of melting peaks and by agarose gel electrophoresis. The following primer pairs were used in this study: SHP-1 (BC002523) forward-TGGCGTGGCAGGA GAACAG and reverse-GCAGTTGGTCACAGAGTAGGGC; SHP-1 promoter I (NM080548) forward-TGGCTTCCCCC TCCCTACAG and reverse-CCCTGGTTCTTGCGACTGG; SHP-1 promoter II (NM002831) forward-ATCTGAGGCTT AGTCCCTGAGC and reverse-CTGAGGTCTCGGTGAAA CCAC; CCL17 (NM002987) forward-CGAGGGACCAATG TGGGC and reverse-GGGTGAGGAGGCTTCAAGACC; CC L11 (NM002986) forward-CACTTCTGTGGCTGCTGCTC and reverse-GCTTTCTGGGGACATTTGC; CCR8 (NM005201) forward-CAGTGTGACAACAGTGACCGAC and reverseGCAATAAAAGACAGCAAGGAGC; ADAM8 (NM001109) forward-ATCCCGAGAGACCCGCTAC and reverse-TGA TTCACCACCTCCAGCAC; Arginase I (NM000045) forward-GACCTGCCCTTTGCTGACATC and reverse-TT GACTTCTGCCACCTTGCC; MCP-1 (NM002982) forwardGCTCATAGCAGCCACCTTC and reverse-GCTTCTTTG GGACACTTGC; Caspase I (NM033294) forward-CATCCT CAGGCTCAGAAGG and reverse-TGTGCGGCTTGACTTG TC; COX-2 (NM000954) forward-GCATCTACGGTT TGCTGTG and reverse-ACTGCTCATCACCCCATTC; GAP DH (NM002046) forward-ACCACCATGGAGAAGGC and reverse-GGCATGGACTGTGGTCATGA.

\section{Western Blotting}

Whole-cell extracts were prepared as previously described. ${ }^{26,30}$ Briefly, macrophages were rinsed with PBS, and then lysed with RIPA buffer. A portion of $10 \mu \mathrm{g}$ of protein per lane was electrophoresed through a $12.5 \%$ polyacrylamide resolving gel and electroblotted to a polyvinylidene difluoride (PVDF) membrane (Millipore Corporation, Burlington, MA, USA). Membranes were blocked with 5\% nonfat dry milk for $1 \mathrm{~h}$, and then incubated with anti-SHP-1 (Upstate, Lake Placid, NY, USA) antibodies followed by horseradish peroxidase conjugated rabbit IgG antibody (DAKO Corporation, Carpinteria, CA, USA) and anti-arginase I (BD Biosciences, San Diego, CA, USA) or anti-actin (MP Biomedicals, Solon, $\mathrm{OH}$ ) followed by horseradish peroxidase conjugated mouse IgG antibody. Enhanced chemiluminescence (Amersham Life Sciences Inc., Cleveland, OH, USA) was used to visualize reactive protein bands on X-ray film. Western blot protein bands were quantified based on pixel density using the Scion Image software. 


\section{Flow Cytometry}

For analysis of STAT6 and STAT1 activation, macrophages were treated with either $10 \mathrm{ng} / \mathrm{ml} \mathrm{IL}-4,100 \mathrm{U} / \mathrm{ml}$ of IFN- $\gamma$, or $10 \mathrm{ng} / \mathrm{ml} \mathrm{TNF}-\alpha$, respectively, for $1 \mathrm{~h}$. Cells were then washed twice with PBS and incubated in $5.0 \mathrm{mM}$ EDTA for $10 \mathrm{~min}$ at $37^{\circ} \mathrm{C}$. Cells were detached with gentle pipetting and received $100 \mu \mathrm{l}$ of $16 \%$ stock formaldehyde per $\mathrm{ml}$ for fixation and then incubated in $90 \%$ methanol at $4{ }^{\circ} \mathrm{C}$ for half an hour to permeabilize cells for intracellular staining. Cells were washed twice with the staining media containing $0.5 \%$ BSA and $0.02 \%$ sodium azide in PBS. Cells were resuspended in a $100 \mu \mathrm{l}$ of staining media and incubated with $20 \mu \mathrm{l}$ of either phosphoSTAT6 (PY-641) with Alexa-488 (612600), phosphoSTAT1 (PY-701) with Alexa-488 (612596), or mouse IgG with Allexa-488 isotype control (557721) (Becton Dickinson, Mountain View, CA, USA). In addition, the levels of total (phosphorylated plus unphosphorylated) STAT6 and STAT1 were concurrently analyzed. Fixed and permeabilized cells were incubated overnight at $4^{\circ} \mathrm{C}$ with either $1 \mu \mathrm{g}$ of rabbit anti-total STAT6 (Santa Cruz, CA, USA), rabbit anti-total STAT1 (Upstate Biotechnology, NY, USA), or rabbit polyclonal IgG for isotype control. The cells were incubated for $3 \mathrm{~h}$ in $1 \mu \mathrm{g}$ of goat anti-rabbit secondary antibody conjugated to PE (Invitrogen).

Furthermore, fixed and permeabilized cells were incubated overnight at $4^{\circ} \mathrm{C}$ with either $1 \mu \mathrm{g}$ of rabbit anti-SHP-1 (Upstate) or rabbit polyclonal IgGs for isotype control. The cells were incubated for $3 \mathrm{~h}$ in $1 \mu \mathrm{g}$ of goat anti-rabbit secondary antibody conjugated to PE (Invitrogen). In addition several extracellular markers were quantified by flow cytometry. $5 \times 10^{5}$ Cells were incubated in $15 \mu \mathrm{l}$ of CD14-APC, CD11bFITC, CD49d-PE $\left(\right.$ anti- $\left.\alpha_{4}\right)$, or CCR2-APC (Becton Dickinson) for $1 \mathrm{~h}$ at room temperature. Cells were analyzed on an LSRII analyzer (Becton Dickinson) and the mean florescence intensity (MFI) was recorded.

\section{NF- $\kappa$ B DNA-Binding Activity Assay}

NF- $\kappa$ B DNA-binding activity was analyzed using the TransAMNF- $\kappa$ B p65 transcription factor assay kit (Active Motif, Carlsbad, CA, USA) following the manufacturer's instructions and as previously described. ${ }^{46-48}$ Briefly, nuclear extracts were prepared ${ }^{26}$ from macrophages of normal subjects and MS patients that were treated with media alone or $20 \mathrm{ng}$ of TNF- $\alpha$ or $5 \mu \mathrm{g} / \mathrm{ml}$ of LPS for $1 \mathrm{~h}$. Protein levels of the nuclear extracts were quantified with the Bradford assay (Pierce Chemicals, Rockford, IL, USA) and $10 \mu \mathrm{g}$ were incubated in a 96-well plate coated with oligonucleotide containing the NF- $\kappa \mathrm{B}$ consensus-binding sequence $5^{\prime}$ GGGACTTTCC- $3^{\prime}$. Bound NF- $\kappa$ B was then detected by a p65-specific primary antibody. An HRP-conjugated secondary antibody was then applied to detect the bound primary antibody and provided the basis for colorimetric quantification. The enzymatic product was measured at $450 \mathrm{~nm}$ with a reference wavelength of $650 \mathrm{~nm}$ by a microplate reader. To quantify the amount of NF- $\kappa \mathrm{B}$, serial dilutions of purified p65 recombinant protein $(20-0.16 \mathrm{ng})$ were measured to provide a calibration curve between $\mathrm{p} 65$ binding and absorbance. The specificity of the assay was further tested by the addition of wild-type or mutated NF- $\kappa \mathrm{B}$ consensus oligonucleotide in the competitive or mutated competitive control wells before the addition of nuclear extracts. The addition of the wild-type NF- $\kappa \mathrm{B}$ consensus oligonucleotide completely abolished NF- $\kappa \mathrm{B}$ binding.

\section{Cytokine ELISA}

The levels of the cytokines TNF- $\alpha$ and IL- 6 were measured using R\&D Systems DuoSet ELISA kits (R\&D Systems) following the manufacturer's protocol.

\section{Nitric Oxide Assay}

The amount of NO produced was measured in amounts of nitrite in macrophage supernatants. Macrophages from normal subjects and MS patients were treated with either media alone, TNF- $\alpha$, IL- 4 , IFN- $\gamma$, or LPS for $18 \mathrm{~h}$ and supernatants were mixed with the Greiss reagent at a 1:1 ratio (Sigma). The reaction was allowed to proceed for $15 \mathrm{~min}$, at which time the absorbance at $540 \mathrm{~nm}$ was quantified with an ELISA plate reader. A calibration curve was generated using sodium nitrite $(1-100 \mu \mathrm{M})$ and used to calculate the amount of nitrite present in macrophage supernatants.

\section{Arginase Activity Assay}

Arginase enzymatic activity was measured as previously described. ${ }^{31,49}$ Briefly, cultured macrophages were lysed in RIPA buffer and incubated in $10 \mathrm{mM} \mathrm{MnCl}_{2}$ and $0.5 \mathrm{M} \mathrm{L}$-arginine at $37^{\circ} \mathrm{C}$ for $75 \mathrm{~min}$. After the assay was stopped by addition of $\mathrm{H}_{3} \mathrm{PO}_{4}$, 1-phenyl-1,2-propanedione-2-oxime (Sigma) was added and the samples were incubated at $100^{\circ} \mathrm{C}$ for $60 \mathrm{~min}$. Urea production by arginase was measured by optical density at $540 \mathrm{~nm}$.

\section{Statistical Analysis}

Histograms contain statistical means with the standard error values. Unless otherwise specified, 27 samples from MS patients and 24 samples from normal subjects were used. In the SHP-1 siRNA experiments samples of macrophages from 15 normal human subjects were used. The $P$ values were generated using the unpaired Student's $t$-test and $P$ values between groups are displayed on histograms. A $P$ value of less than 0.05 was chosen to indicate statistical significance between two sample means.

\section{RESULTS}

\section{Characterization of Adhesion/Activation Molecules in Blood-Derived Macrophages of MS Patients and Normal Subjects}

The expression levels of multiple macrophage markers were quantified by flow cytometry in cultured macrophages of normal subjects and MS patients (Figure 1). More than 95\% of the cells stained for CD14 and no significant differences in 

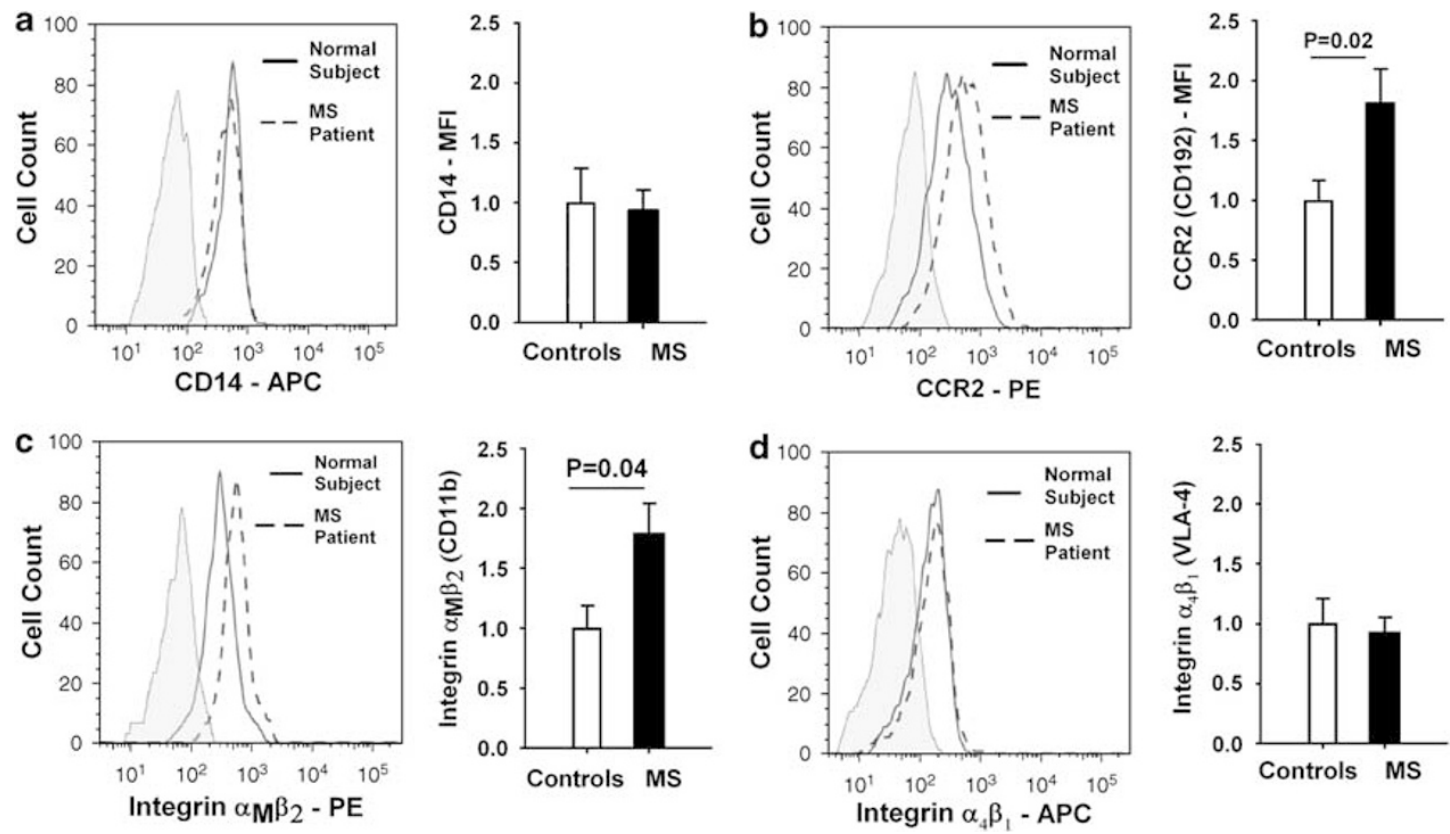

Figure 1 The levels of several extracellular markers/adhesion molecules were quantified in macrophages of MS patients and normal subjects using flow cytometry. Macrophages of MS patients and normal subjects were stained with antibodies against (a) CD14, (b) CD192 (CCR2), (c) CD11b ( $\left.\alpha_{M}\right)$, and (d) VLA-4 $\left(\alpha_{4}\right)$. The histogram overlays are labeled as follows: shaded histogram for isotype control, solid line for normal subject, and dashed line for MS patient. The levels of each antigen were quantified based on the relative mean fluorescence intensity (MFI) and normalized to normal subjects represented as 1.

levels of expression were observed between the subject groups (Figure 1a). Furthermore, we examined the expression of CCR2 (CD192), which is the receptor for the chemokine MCP-1 and a marker for inflammatory monocytes. ${ }^{50} \mathrm{Im}$ portantly, macrophages of SHP-1 deficient mice display increased levels of CCR2.$^{51,52}$ Macrophages of MS patients had significantly higher levels of CCR2 compared to normal subjects indicating that MS-derived macrophages have a relatively heightened inflammatory state. As such, we characterized two other potential activation markers on these cells. We analyzed the antigenic determinants of CD11b $\left(\alpha_{\mathrm{M}} \beta_{2}\right.$ integrin) and VLA4 $\left(\alpha_{4} \beta_{1}\right.$ integrin $)$, which have been shown to be important in the trafficking, adhesion, phagocytosis, and migration of macrophages at inflammatory sites. ${ }^{53-56}$ Integrin $\alpha_{\mathrm{M}} \beta_{2}$ expression was significantly higher in the macrophages of MS patients compared to normal subjects. In contrast, the expression of integrin $\alpha_{4} \beta_{1}$ was not significantly different between macrophages of MS patients and normal subjects.

\section{SHP-1 Protein and mRNA are Lower in Macrophages of MS Patients}

We have previously described that PBMCs of MS patients have decreased expression of SHP-1 compared to normal subjects. ${ }^{25}$ Cultured macrophages of MS patients had significantly lower levels of SHP-1 protein than those of normal subjects measured by intracellular flow cytometry (Figure 2a and $b$ ). To corroborate these findings, the levels of SHP-1 protein in macrophages were measured by western immunoblotting (Figure 2c). On average, SHP-1 levels in macrophages of MS patients were half the levels of SHP-1 in cells of normal subjects.

To examine whether macrophages of MS patients displayed a deficiency in SHP-1 at the transcriptional level, the levels of SHP-1 mRNA were quantified using primers flanking the coding region of the gene common to both transcripts (Figure 3). SHP-1 mRNA levels in macrophages were significantly lower in MS patients compared to normal subjects (Figure 3a). Furthermore, analysis of SHP-1 mRNA expression in individual subject groups did not show any statistically significant correlation between either age or gender and SHP-1 levels (data not shown).

\section{SHP-1 Promoter II Transcripts are Selectively Lower in MS Patients}

To determine the individual contribution of each of two known transcripts on the expression levels of SHP-1 in macrophages, promoter I and II transcript copy numbers were measured using promoter-specific RT-PCR primers. Constitutive levels of SHP-1 promoter I transcripts were not significantly lower in macrophages in MS patients compared to control subjects (Figure 3c). On the other hand, constitutive levels of SHP-1 promoter II transcripts were significantly lower in macrophages of MS patients compared to control subjects (Figure 3d). Taken together, we concluded that macrophages of MS patients have constitutively lower 
a

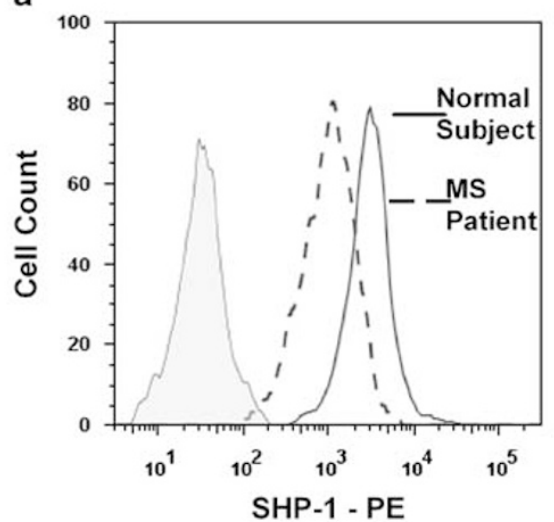

b

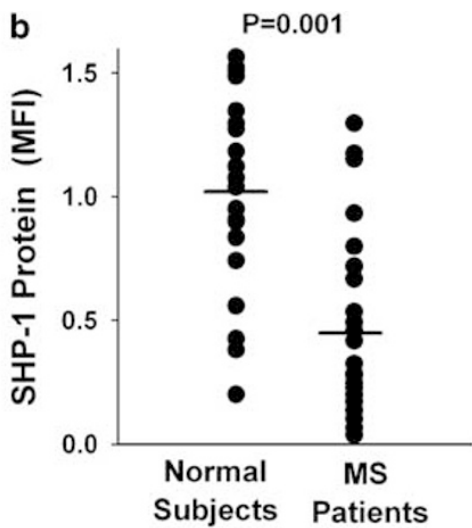

C

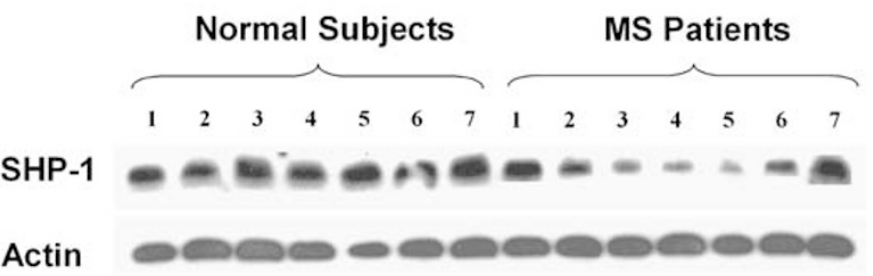

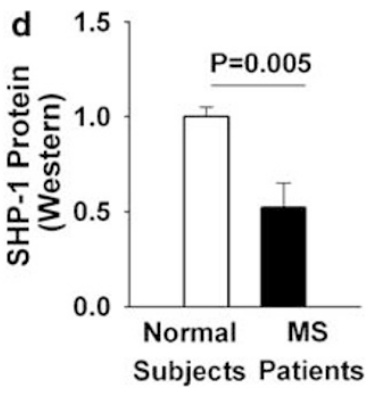

Figure 2 SHP-1 protein expression in macrophages of MS patients compared to normal subjects (a) SHP-1 protein levels of MS patients and normal subjects were measured with intracellular flow cytometry. The histograms are labeled as follows: shaded histogram for isotype control, solid line for normal subject, and dashed line for MS patient. (b) SHP-1 expression was measured by flow cytometry and quantified using the mean fluorescence intensity (MFI). SHP-1 levels from 24 normal subjects and 27 MS patients were normalized to average SHP-1 levels in normal subjects represented as 1. (c) Western blot analysis of SHP-1 and actin in macrophages MS patients compared to normal subjects. (d) SHP-1 protein in macrophages of MS patients and normal subjects measured by western immunoblot was quantified by measuring the pixel density.

levels of SHP-1 protein and mRNA compared to normal subjects and furthermore that a lack in promoter II transcripts is primarily responsible for this deficiency.

\section{Analysis of STAT6 and STAT1 Activation in MS Macrophages}

SHP-1 regulates phosphorylation of several STATs by enzymatic removal of the phosphate group from tyrosine either on activated cytokine receptors or downstream signaling molecules. Thus, SHP-1 modulates STAT activation, translocation into the nucleus, and transcriptional activity on responsive genes. As several studies showed that SHP-1 stringently modulates IL-4R $\alpha /$ STAT6 signaling molecules, ${ }^{31,32,34,57}$ and STAT6 was shown to be elevated in MS, ${ }^{23-25}$ we examined STAT6 activation in macrophages from MS patients (Figure 4). For analysis, we measured the level of total STAT6 (unphosphorylated plus phosphorylated) and tyrosine phosphorylated STAT6 (pSTAT6) in macrophages using intracellular flow cytometry. As expected, macrophages of MS patients had significantly elevated constitutive phosphorylation of STAT6 compared to macrophages of normal subjects (Figure $4 \mathrm{~b}$ ). In contrast, there were no differences in the expression levels of total STAT6 protein (Figure 4a), verifying that the differences observed in pSTAT6 levels are attributed to the relative phosphorylation state of STAT6. Staining the same cells for SHP-1 revealed a reciprocal expression pattern of SHP-1 and pSTAT6, such that lower constitutive levels of SHP-1 in MS patients correlated with higher pSTAT6 levels compared to macrophages of normal subjects (data not shown). Furthermore, macrophages were treated for $1 \mathrm{~h}$ with IL-4, which induces phosphorylation of STAT6, to determine possible differences in STAT6 activation following engagement of the IL-4 receptor. Treatment with IL-4 caused higher phosphorylation of STAT6 in macrophages of MS patients compared to normal subjects (Figure 4b). Similar results were obtained when macrophages were treated with IL-13, another cytokine that mediates STAT6 activation via IL-4R $\alpha$ (data not shown).

Apart from STAT6, there are several other transcription factors that are elevated in MS patients and are controlled by SHP-1. In particular, tyrosine phosphorylated STAT1 (pYSTAT1) that mediates interferon signaling was found to be elevated in MS patients ${ }^{20,21}$ and is controlled by SHP-1. ${ }^{29,30,58,59}$ Therefore, we characterized STAT1 activation by measuring the level of total STAT1 (unphosphorylated plus phosphorylated, STAT1) and tyrosine phosphorylated STAT1 (pSTAT1) in macrophages using intracellular flow cytometry. No differences were observed in total STAT1 

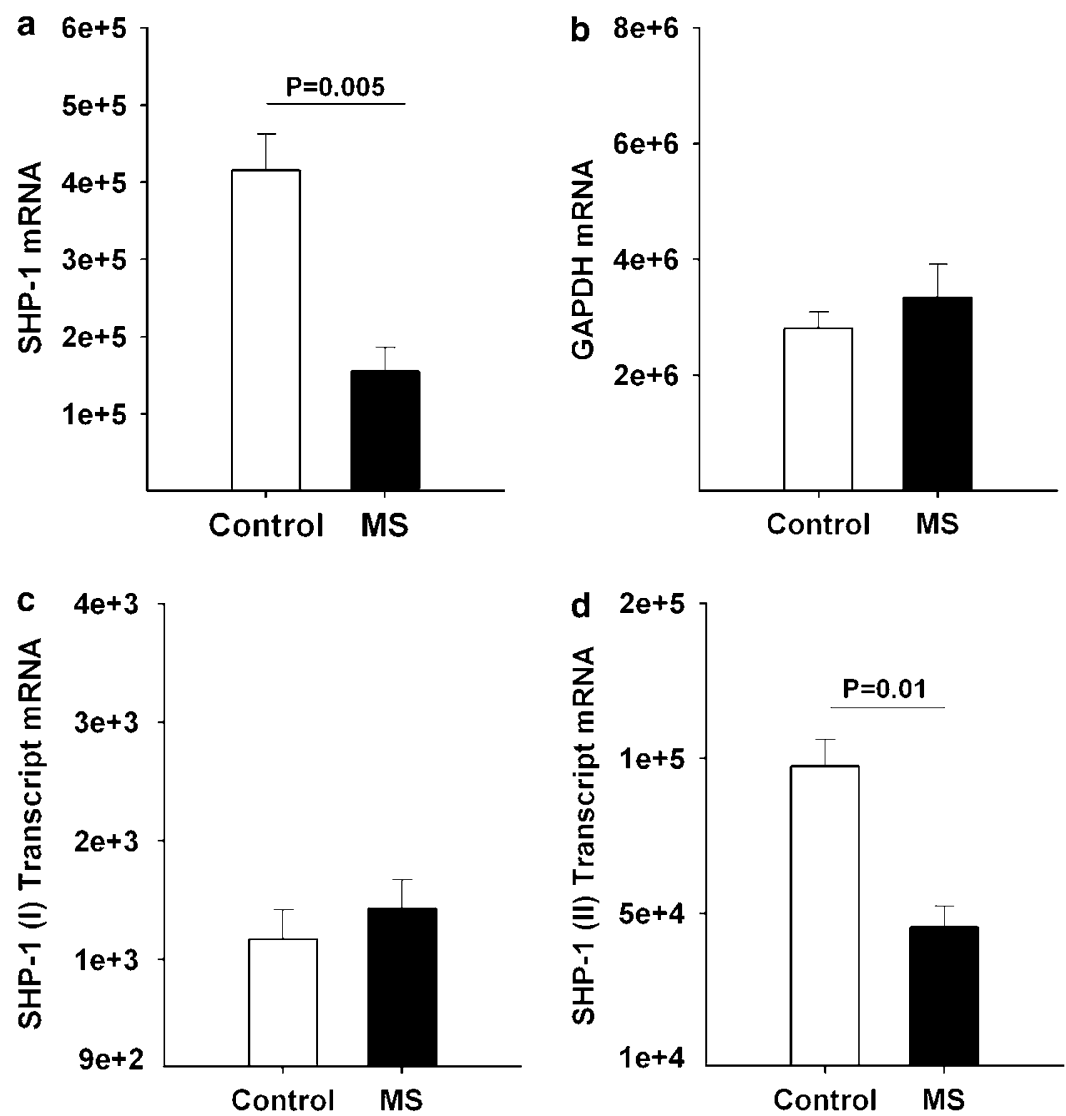

Figure 3 SHP-1 mRNA levels in macrophages of MS patients compared to normal subjects. The absolute mRNA transcript copy numbers per $10 \mathrm{ng}$ of total RNA were quantified using real-time RT-PCR in MS patients and normal subjects. (a) The levels of the common SHP-1 transcript, (b) the housekeeping gene GAPDH, (c) the SHP-1 promoter I transcripts, and (d) the SHP-1 promoter II transcripts were quantified with real-time RT-PCR in macrophages of MS patients and normal subjects.

protein (Figure 4c). Constitutive pSTAT1, although higher, was not significantly elevated in macrophages of MS patients compared to normal subjects (Figure $4 \mathrm{~d}$ ). However, $1 \mathrm{~h}$ treatment with IFN- $\gamma$ resulted in higher phosphorylation of STAT1 in macrophages of MS patients compared to normal subjects (Figure $4 \mathrm{~d}$ ). Taken together, these data suggest that both STAT6 and STAT1 show enhanced cytokine-mediated activation in macrophages of MS patients, in accordance with SHP-1 deficiency relative to normal subject macrophages.

\section{Elevated Expression of NF- $\kappa$ B DNA-Binding Activity and TNF- $\alpha$ /IL- 6 Secretion in Macrophages of MS Patients}

Another important transcription factor involved in the pathogenesis of MS is NF- $\kappa$ B..$^{19,60}$ Notably, NF- $\kappa$ B activation was observed in inflammatory macrophages in MS CNS lesions. ${ }^{61}$ Several reports have documented the negative regulation of NF- $\kappa$ B by SHP-1. ${ }^{26,27,59,62,63}$ Therefore, it was important to examine NF- $\kappa \mathrm{B}$ activation in macrophages of MS patients (Figure 5a). Macrophages from normal subjects and MS patients were treated with medium alone, TNF- $\alpha$, or LPS and then nuclear extracts were isolated and allowed to bind an NF- $\kappa \mathrm{B}$ consensus oligonucleotide sequence. Bound $\mathrm{NF}-\kappa \mathrm{B}$ was then detected by a p65 (RelA)-specific antibody and quantified based on a calibration curve generated by using a purified p65 recombinant protein. Constitutively, NF- $\kappa \mathrm{B}$ binding was slightly, but significantly elevated in macrophages of MS patients compared to normal subjects (Figure 5a). Furthermore, treatment with either TNF- $\alpha$ or LPS dramatically increased NF- $\kappa \mathrm{B}$ binding and importantly nuclear extracts from macrophages of MS patients showed significantly increased binding compared to macrophages of normal subjects.

In addition, we quantified the secretion of the NF- $\kappa \mathrm{B}$ responsive proinflammatory cytokines TNF- $\alpha$ and IL-6 from macrophages of MS patients compared to normal subjects, because it was previously shown that a deficiency in SHP-1 leads to higher expression of these cytokines. ${ }^{9,27,62,64-66}$ Macrophages were cultured for $18 \mathrm{~h}$ with either media alone, TLR ligands, or TNF- $\alpha$ and the supernatants were analyzed for the presence of TNF- $\alpha$ or IL- 6 (Figure $5 b$ and c). Constitutively, the levels of TNF- $\alpha$ and IL- 6 were slightly but significantly elevated in supernatants of macrophages from MS patients compared to normal subjects. Furthermore, stimulation of macrophages with LPS or dsRNA resulted in a substantial induction of TNF- $\alpha$ and IL- 6 in both subject groups but the induction was significantly higher in 

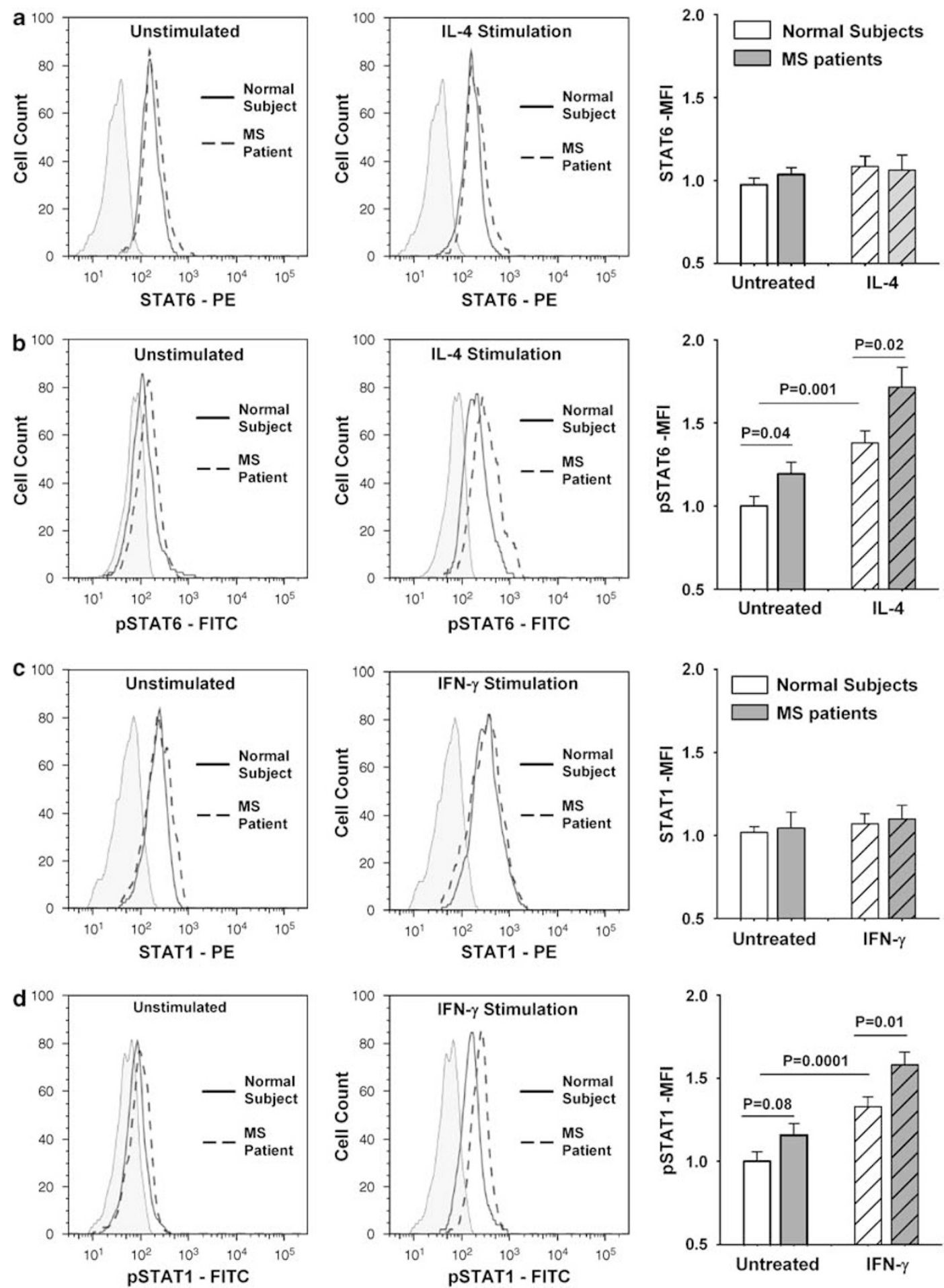

Figure 4 STAT6 and STAT1 activation in macrophages of MS patients and normal subjects. Total STAT6, tyrosine phosphorylated STAT6 (pSTAT6), total STAT1, and tyrosine phosphorylated STAT1 (pSTAT1) levels in macrophages of MS patients compared to normal subjects. Macrophages of MS patients and normal subjects were fixed, permeabilized, and stained with antibodies against total STAT6, pSTAT6, STAT1, or pSTAT1. The histogram overlays are labeled as follows: shaded histogram for isotype control, solid line for normal subject, and dashed line for MS patient. (a and b) The levels of STAT6 and pSTAT6 were quantified based on the relative MFI in macrophages of MS patients and normal subjects before and after 1-h treatment with IL-4. (c and d) The levels of STAT1 and PSTAT1 were quantified based on the relative MFI in macrophages of MS patients and normal subjects before and after 1-h treatment with IFN- $\gamma$. 


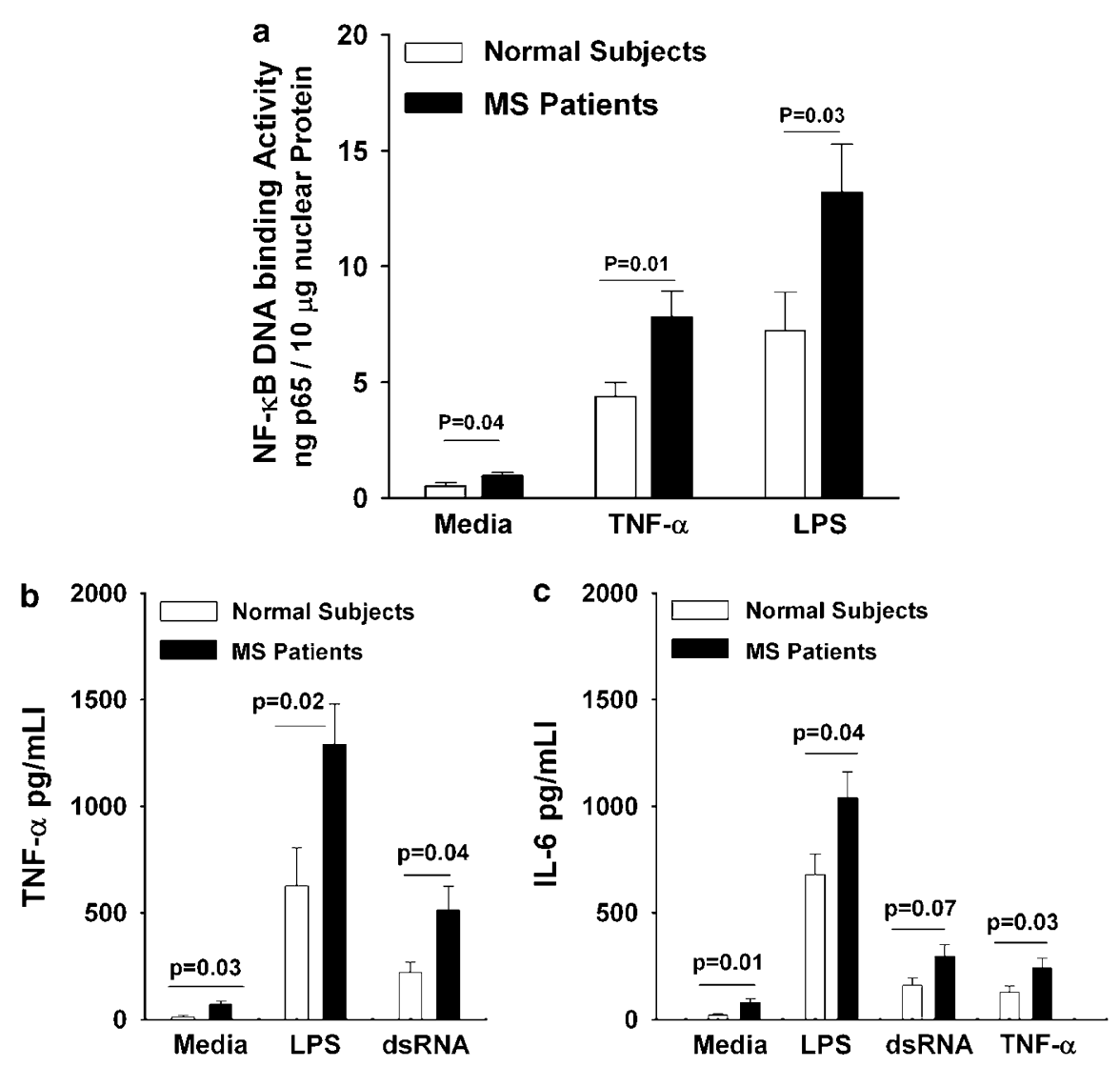

Figure $5 \mathrm{NF}-\kappa \mathrm{B}$ activation in macrophages of MS patients and normal subjects. (a) Macrophages from normal subjects and MS patients were treated with media alone, TNF- $\alpha$, or LPS for $1 \mathrm{~h}$ and nuclear extracts were isolated and allowed to bind an NF- $\kappa$ B consensus-binding sequence. Bound NF- $\kappa$ B was then detected by a p65-specific antibody and quantified based on a calibration curve generated by using a purified p65 recombinant protein. The NF- $\kappa$ B DNA binding activity is reported as ng of bound p65 protein per $10 \mu \mathrm{g}$ of macrophage nuclear extracts. (b and c) TNF- $\alpha$ and IL- 6 secretion was quantified in macrophages of MS patients and normal subjects. Macrophages were cultured in media alone or in the presence of the TLR ligands, LPS and dsRNA for $18 \mathrm{~h}$ and supernatants were analyzed for TNF- $\alpha$ or IL- 6 by ELISA.

macrophages of MS patients compared to normal subjects. In all, these data demonstrate that macrophages of MS patients display an enhanced expression of NF- $\kappa$ B-responsive genes both constitutively and after stimulation with TLR ligands and cytokines that induce NF- $\kappa \mathrm{B}$.

\section{Heightened Expression of STAT6-, STAT1-, and NF- $\kappa$ B-Responsive Genes in MS Macrophages}

To determine whether increased activation of STAT6, STAT1, and NF- $\kappa \mathrm{B}$ in macrophages of MS patients relative to normal subjects corresponded to heightened expression of STAT6-, STAT1-, and NF- $\kappa$ B-responsive genes, the mRNA levels of several genes were quantified following 18 -h treatment with several cytokines (Figure 6). The expression levels of STAT6responsive chemokines were of particular interest because these mediate trafficking, maturation, and attraction of lymphocytes and macrophages to areas of CNS inflammation. ${ }^{14}$ CCL17/TARC ${ }^{67,68}$ and CCL11/Eotaxin ${ }^{69}$ were substantially induced in macrophages following IL-4 treatment and importantly macrophages of MS patients showed significantly higher induction compared to macrophages of normal subjects (Figure 6a and b). Similar results were obtained when macrophages were treated with IL-13 (data not shown). Similarly, the mRNA of ADAM8, a STAT6-responsive disintegrin matrix metalloproteinase ${ }^{70,71}$ that may be involved in demyelination, ${ }^{72}$ was induced at higher levels in macrophages of MS patients compared to macrophages of normal subjects following IL-4 treatment (data not shown). Taken together, in agreement with depressed SHP-1 levels, macrophages of MS patients display increased STAT6 activation and increased expression of STAT6-responsive genes.

Furthermore, as SHP- 1 controls STAT1 activation, ${ }^{29,30,58,73}$ we examined the expression of STAT1-responsive genes following cytokine stimulation (Figure 6). The chemokine IP10, a STAT1-inducible chemokine that was previously shown to be elevated in MS, ${ }^{74-78}$ was highly induced by IFN- $\gamma$ and moderately induced by LPS in MS macrophages. Moreover, IP-10 was induced to significantly higher levels in MS macrophages compared to normal subject macrophages (Figure 6c). Similarly, caspase 1, a STAT1-inducible enzyme involved in $\mathrm{IL}-1 \beta$-mediated inflammation, ${ }^{79-81}$ was significantly 

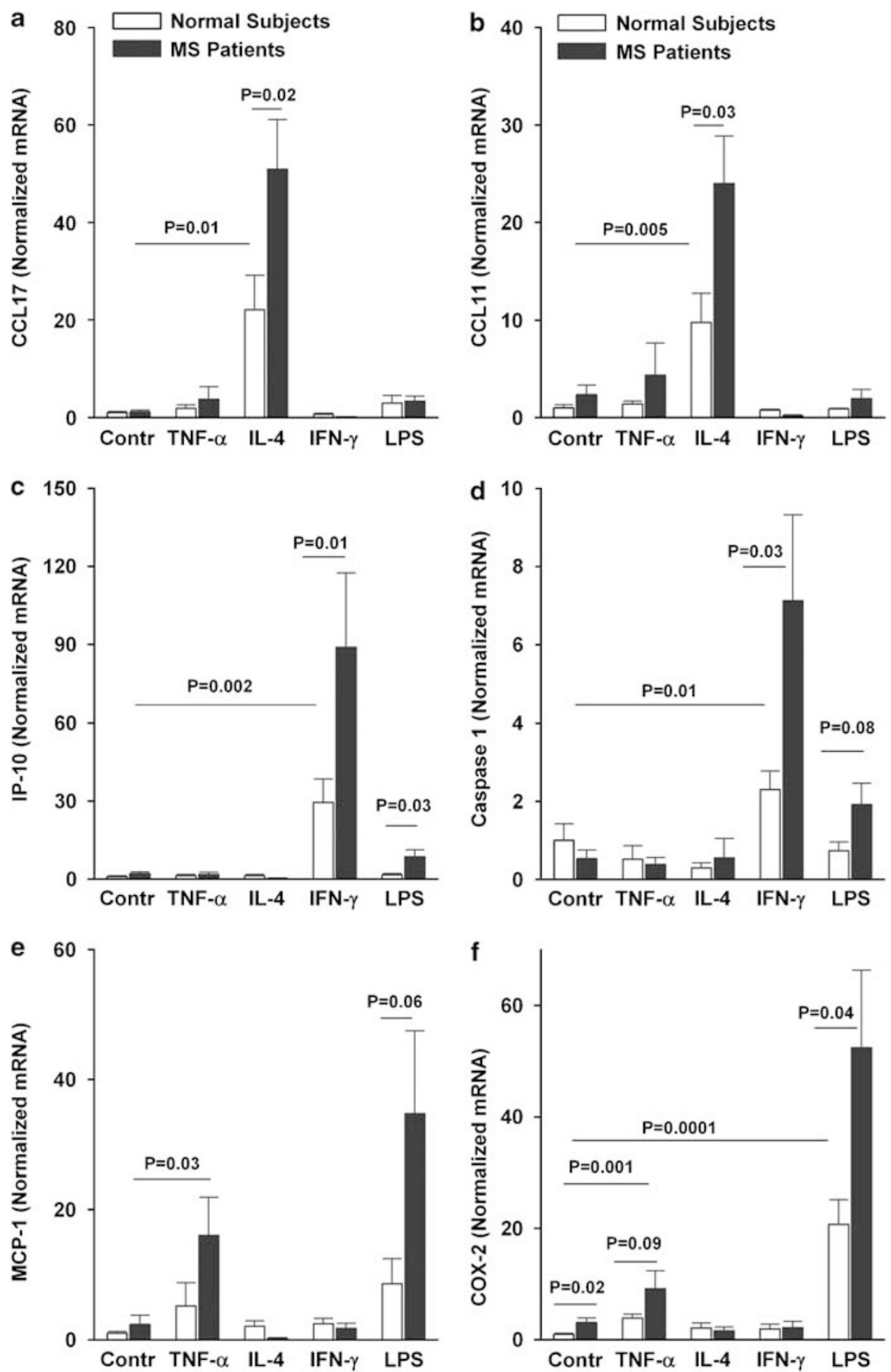

Figure 6 Gene profile of macrophages of MS patients and normal subjects. A number of genes that are STAT6- (a, b), STAT1- (c, d), or NF- $\kappa$ B- $(\mathbf{e}, \mathbf{f})$ inducible were quantified in macrophages of normal subjects and MS patients before and after 18-h treatment with TNF- $\alpha$, IL-4, IFN- $\gamma$, and LPS. Real-time RT-PCR was used to measure the mRNA levels of CCL17/TARC, CCL11/eotaxin, CXCL10/IP-10, Caspase I, CCL2/MCP-1, and cyclooxygenase II (COX-2). The actual transcript copy number of each gene is reported in relation to the untreated normal subjects, which is designated as 1.

induced to higher levels by IFN- $\gamma$ in MS macrophages compared to macrophages of normal subjects (Figure 6d). These data suggest that STAT1 phosphorylation and STAT1-responsive genes show enhanced activation in macrophages of MS patients compared to macrophages of normal subjects.
Moreover, as NF- $\kappa \mathrm{B}$ binding was elevated in macrophages of MS patients, we wanted to examine whether NF- $\kappa$ B-responsive genes were elevated in macrophages of MS patients. Therefore, we quantified the expression of the NF- $\kappa \mathrm{B}$ inducible chemokine MCP-1 and cyclooxygenase-2 (COX-2) $)^{82,83}$ with real-time RT-PCR (Figure 6e and f). MCP-1 and COX-2 
genes showed substantially higher induction in macrophages of MS patients compared to normal subjects following treatment with either TNF- $\alpha$ or LPS. These data further demonstrate that NF- $\kappa \mathrm{B}$ activation and NF- $\kappa \mathrm{B}$-responsive genes are elevated in macrophages of MS patients compared to normal subjects.

\section{Arginase I and iNOS Expression and Activity are Enhanced in Macrophages of MS Patients}

Several reports in mouse models point to the importance of different macrophage activation profiles in specific types of inflammatory diseases. ${ }^{84}$ Recently characterized macrophage profiles are the classically activated (or M1 macrophages) that display increased STAT1/NF- $\kappa$ B-responsive genes including inducible nitric oxide synthase (iNOS) and alternatively activated (or M2 macrophages) that display increased STAT6-responsive genes including arginase I. Interestingly, there is usually a profound antagonism of differentiation toward either M1 or M2 macrophage activation profile such that dual expression of iNOS and arginase I is seldom observed. ${ }^{85-88}$ Using this paradigm, we determined whether MS macrophages might be preferentially skewed toward either the M1 or the M2 profile relative to those of normal subjects.

Examination of constitutive iNOS mRNA expression and nitric oxide (NO) production showed no differences between MS and normal subject macrophages (Figure 7). TNF- $\alpha$ and IFN- $\gamma$ moderately and LPS substantially induced iNOS
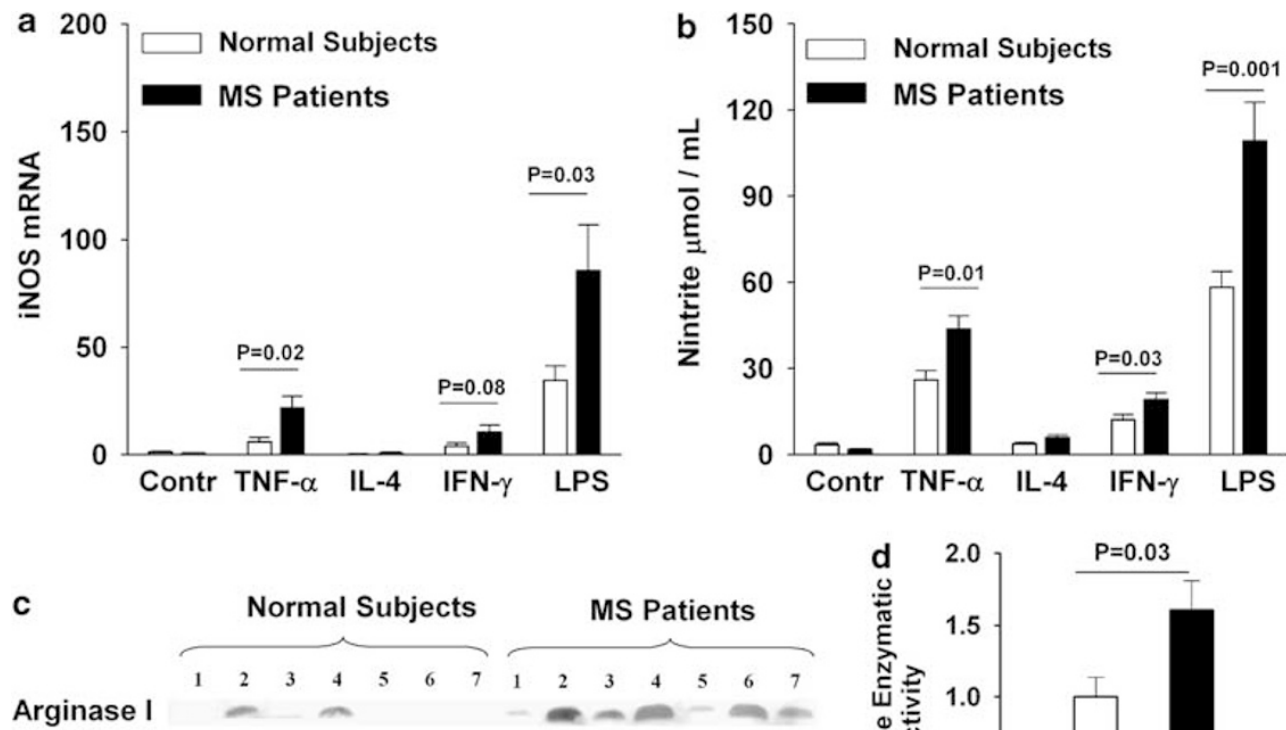

Actin
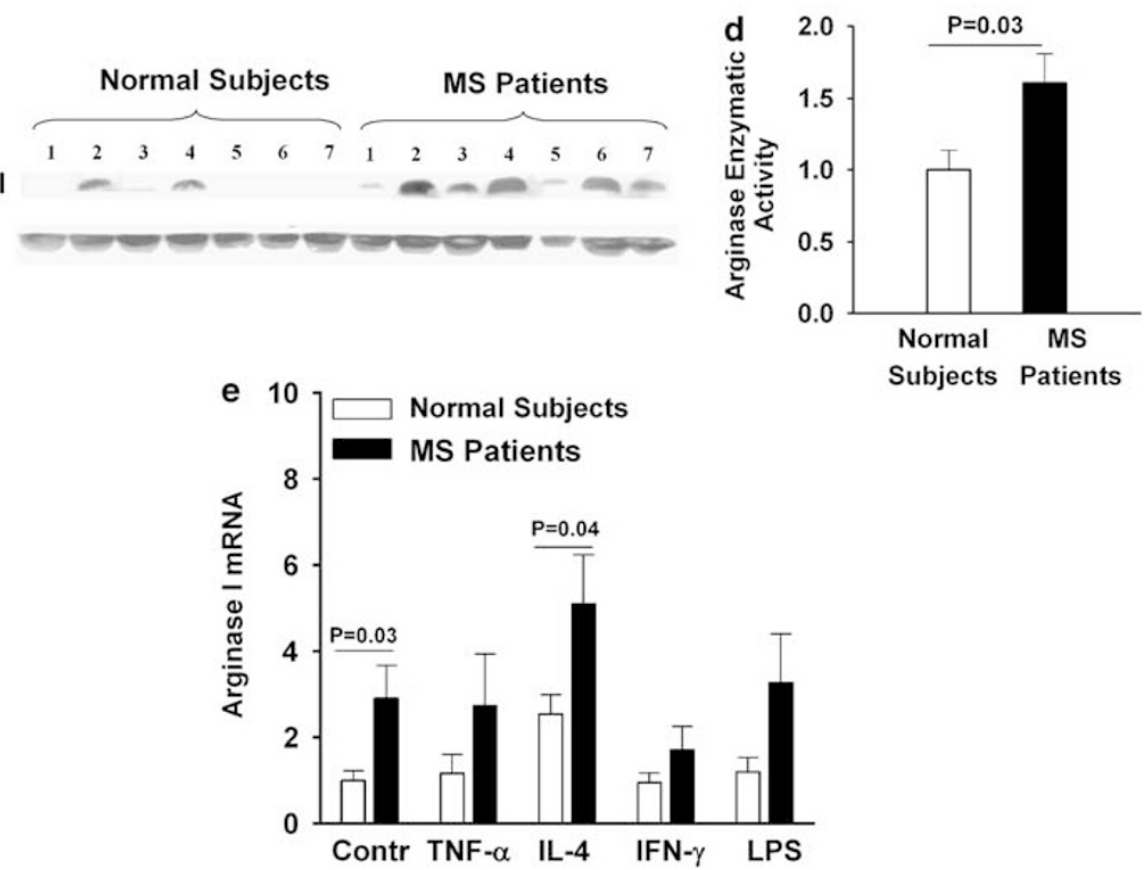

Figure 7 Arginase I and iNOS expression and activity in macrophages of MS patients and normal subjects. (a) Inducible nitric oxide synthase (iNOS) mRNA expression was quantified in macrophages of normal subjects and MS patients before and after 18-h treatment with TNF- $\alpha$, IL-4, IFN- $\gamma$, and LPS by real-time RT-PCR. (b) Similarly, the levels of nitrite, as an indicator of nitric oxide (NO) production, were quantified in the supernatants of macrophages from MS patients and normal subjects that were treated with TNF- $\alpha$, IL-4, IFN- $\gamma$, and LPS. (c) Arginase I and actin protein expression were measured in macrophages of MS patients compared to normal subjects by western blot analysis. (d) The enzymatic activity of arginase was quantified in macrophages of MS patients and normal subjects. (e) Arginase I mRNA expression was quantified in macrophages of normal subjects and MS patients before and after 18-h treatment with TNF- $\alpha$, IL-4, IFN- $\gamma$, and LPS by real-time RT-PCR. 
mRNA expression and NO production in macrophages (Figure $7 \mathrm{a}$ and $\mathrm{b}$ ). Importantly, macrophages from MS patients showed a significantly higher iNOS mRNA expression and NO production following cytokine stimulation compared to macrophages from normal subjects. With respect to constitutive arginase I expression, we found higher levels of both arginase I protein, mRNA, and enzymatic activity in MS compared to normal subject macrophages (Figure $6 \mathrm{c}-\mathrm{e}$ ). Moreover, when macrophages were exposed to M2-inducing cytokine IL-4, MS macrophages expressed more arginase I than normal subject macrophages. These data indicated that MS macrophages may be constitutively skewed toward M2 activation profile in vitro and this skewing may be further reinforced by IL-4. Nonetheless, MS macrophages also display M1 skewedness relative to normal subject macrophage following exposure to M1-inducing cytokines such as IFN- $\gamma$ and TNF- $\alpha$. The latter indicates the extreme plasticity of MS macrophages relative to normal subject macrophages and the potential importance of the cytokine milieu in determining the ultimate balance between M1 and M2 phenotype of these cells.

\section{SHP-1 Depletion in Normal Subject Macrophages Enhances their Inflammatory Profile}

To examine whether decreased SHP-1 levels are directly responsible for transcription factor activation and inflammatory gene expression in macrophages, macrophages of normal subjects were treated with siRNA to acutely deplete SHP-1 (Figure 8). First, we observed that SHP-1 protein was substantially depleted by more than fivefold in the macrophages treated with the SHP-1 siRNA compared to the macrophages treated with control siRNA of scrambled sequence (Figure 8a). Accordingly, SHP-1 depletion resulted in a considerable increase of the STAT6-responsive arginase I protein (Figure 8a) and mRNA (data not shown).

Further, we investigated whether lowered SHP-1 levels in normal human macrophages treated with siRNA led to enhanced activation of STAT6 and STAT1. SHP-1 depletion resulted in a significant increase in constitutive STAT6 phosphorylation and to a significantly higher induction of pSTAT6 in response to 1-h treatment with IL-4 (Figure 8b). Similar results were obtained when macrophages were treated with IL-13, another cytokine that mediates STAT6 activation via IL-4R $\alpha$ (data not shown). In addition, although SHP-1 depletion did not result in a significant increase of constitutive STAT1 phosphorylation, IFN- $\gamma$ treatment for $1 \mathrm{~h}$ induced significantly higher PSTAT1 levels in SHP-1-depleted macrophages compared to control macrophages treated with scrambled siRNA (Figure 8c). To further validate that SHP-1 controls STAT6 and STAT1 activations, we examined the expression of STAT6- and STAT1-responsive genes in macrophages of normal subjects that were treated with either scramble siRNA or SHP-1 siRNA. The STAT6-inducible genes CCL17 (Figure 8d), Arginase I, CCL11, and ADAM8 (data not shown) were significantly induced to higher levels in
SHP-1-depleted macrophages following an 18-h IL-4 stimulation. Similarly, the STAT1-inducible genes IP-10 (Figure 8e) and caspase 1 (data not shown) were induced at significantly higher levels in SHP-1-depleted macrophages following IFN$\gamma$ treatment. Taken together, these results point to the important role of SHP-1 in downmodulating proinflammatory STAT6 and STAT1 activities in human macrophages.

Furthermore, we examined the role of SHP-1 in controlling NF- $\kappa \mathrm{B}$-responsive genes in human macrophages. First mRNA levels of the NF- $\kappa \mathrm{B}$-inducible chemokine MCP-1 (Figure 8f) and COX-2 (data not shown) were induced at significantly higher levels in SHP-1-depleted macrophages following TNF- $\alpha$ or LPS treatment. Furthermore, the secretion of TNF- $\alpha$ and IL-6 in SHP-1-depleted macrophages was significantly higher following LPS or dsRNA stimulation compared to macrophages treated with scramble siRNA (Figure $8 \mathrm{~h}$ and i). Additionally, TNF- $\alpha$ or LPS treatment led to a significantly higher production of NO in SHP-1-depleted macrophages compared to macrophages treated with scramble siRNA (Figure 8g). Taken together, we concluded that depressed levels of SHP-1 in human macrophages led to a unique coactivation of STAT6/STAT1/NF- $\kappa$ B-responsive proinflammatory genes relative to normal subject macrophages. With the observation of heightened CCR2 (Figure 1), we propose that MS macrophages may be inherently inflammatory in nature.

\section{DISCUSSION}

In multiple sclerosis and animal models for MS, intense macrophage infiltration is present in active demyelinating lesions and both their numbers and differentiation/activation correlates with disease severity. ${ }^{2,4,5,89,90}$ Macrophages can mediate myelin phagocytosis, degradation, oligodendrogliopathy, and axonal loss both through cell-mediated processes and the secretion of inflammatory mediators. ${ }^{1,7,90,91}$ Based on our recent report of increase demyelinating activity of macrophages in me/me mice, ${ }^{9}$ a key question was whether macrophages of MS patients display similar defects in modulation of proinflammatory cytokine signaling that may contribute to activated inflammatory profile and demyelinating activity.

Therefore, we analyzed the expression and function of SHP-1 as a possible cause of enhanced macrophage inflammatory activity in MS. Examining monocyte-derived macrophages from MS patients and normal subjects revealed that SHP-1 was deficient in macrophages of MS patients. Interestingly, this SHP-1 deficiency corresponded to a diminished expression of SHP-1 promoter II transcripts suggesting a specific alteration in promoter II function in MS. Accordingly, macrophages from MS patients displayed enhanced STAT6, STAT1, and NF- $\kappa$ B activity, transcription factors that were previously shown to be modulated by SHP-1 in various cell types including mouse macrophages. ${ }^{9}$ In turn, several STAT6-, STAT1-, and NF- $\kappa$ B-inducible genes that have been shown to play roles in the mechanism of 
inflammatory demyelination were shown to be both higher in macrophages of MS patients and regulated by SHP-1.

The relevance of the present findings to the pathogenetic mechanisms of MS is supported by previous reports on activation of signaling molecules in the CNS of MS subjects that are regulated by SHP-1. For instance, phosphorylated STAT6 was found to be highly expressed in MS lesions, ${ }^{24}$ normal appearing white matter of MS patients ${ }^{23}$ and leukocytes of MS patients. ${ }^{25}$ Furthermore, macrophages of mice that lack SHP-1 show increased constitutive activation of STAT6 and heightened levels of STAT6-inducible genes. ${ }^{25}$

a
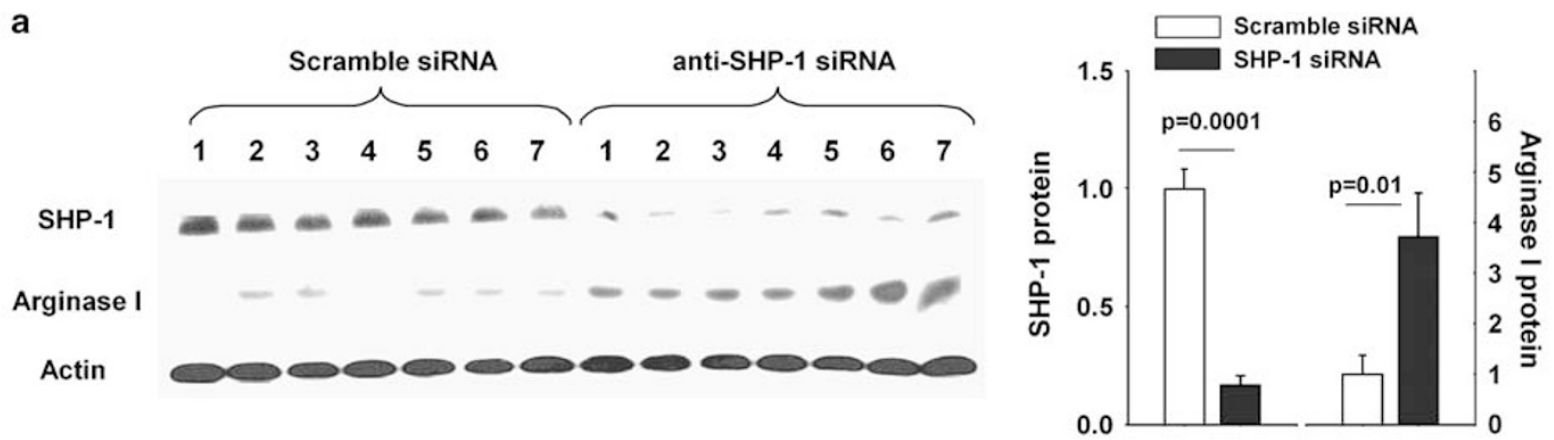

b
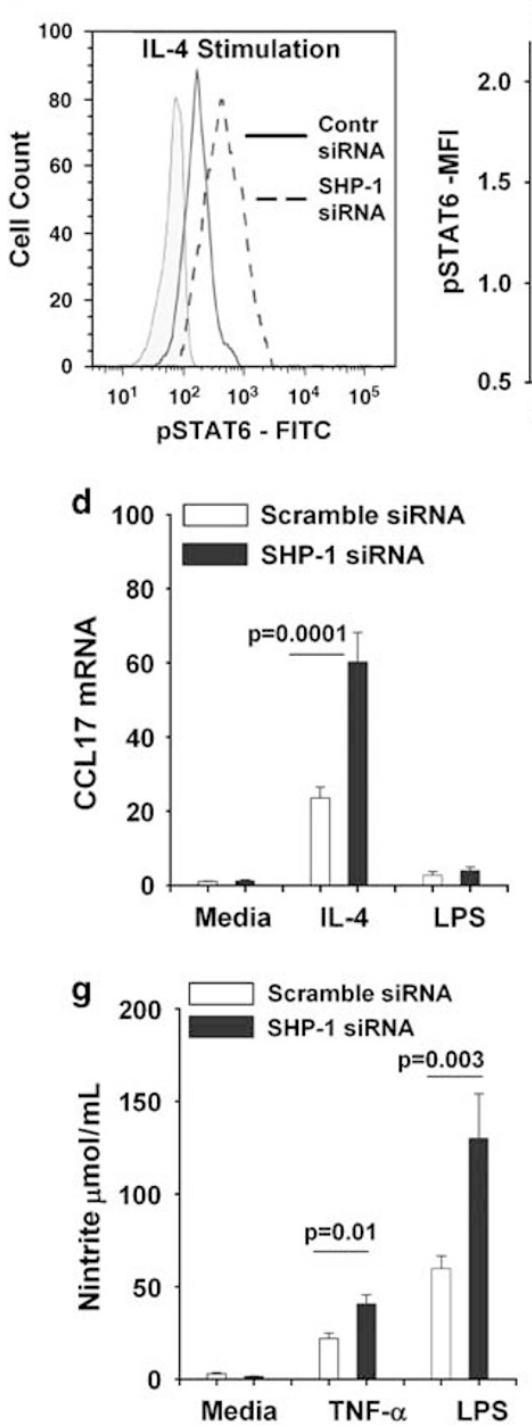

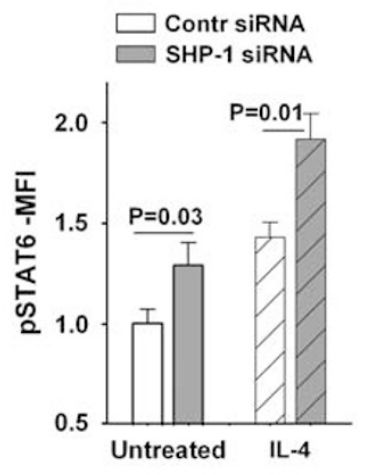

C

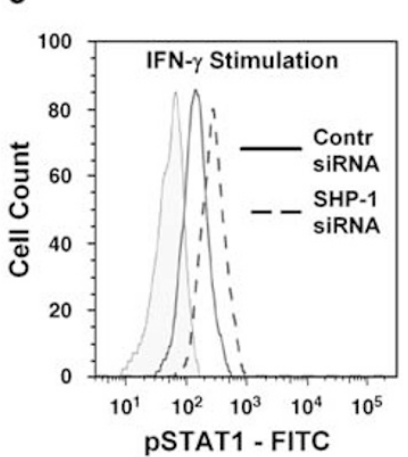

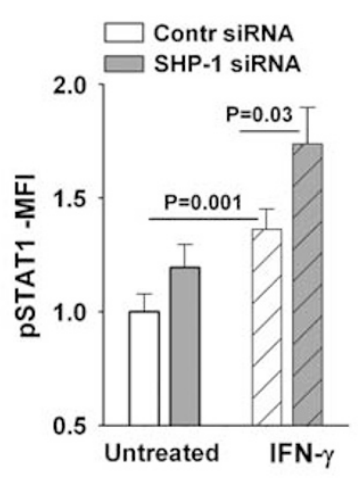
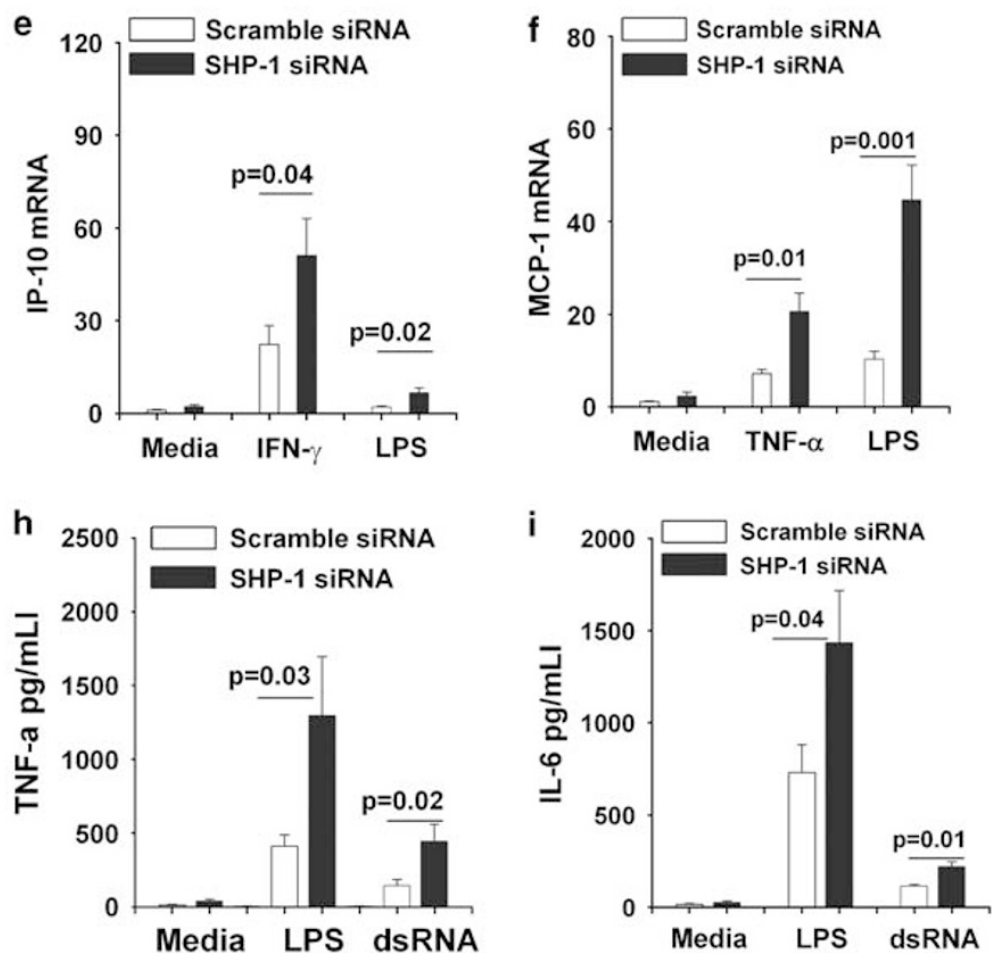
Moreover, the lack of SHP-1 leads to severe macrophagemediated CNS demyelination following TMEV infection. ${ }^{9,31,37}$ Thus, this study suggests that STAT6 activation and expression of several genes with confirmed STAT6-responsive elements in macrophages may have functional significance to the pathophysiology of MS. For example, the chemokines CCL17/TARC and CCL11/Eotaxin, which attract inflammatory cells to demyelinating lesions, were elevated in macrophages of MS patients and the expression of these chemokines is controlled by SHP-1. ${ }^{92-94}$

Analysis of other STAT6-responsive genes showed that the matrix metalloproteinase ADAM8 is elevated in macrophages of MS patients and SHP- 1 controls its expression. Proteinases may be involved in the pathogenesis of MS, because these can mediate the proteolysis of extracellular matrix molecules, disrupt the blood brain barrier, and promote leukocyte entry into the brain parenchyma. ${ }^{95}$ ADAM8 which is highly expressed in macrophages was shown to hydrolyze myelin basic protein $^{72}$ and can, therefore, directly contribute to demyelination. In addition, arginase I is a STAT6-responsive gene that has been shown to be constitutively elevated in the CNS of SHP-1-deficient mice and plays an important role in virus-induced demyelinating disease. ${ }^{31}$ Also, arginase I inhibition results in attenuation of EAE onset and progression. ${ }^{73}$ Interestingly, the increased levels of arginase I in MS macrophages might make these cells more susceptible to viral infections relevant to MS pathogenesis. ${ }^{31}$ Although the mechanism by which arginase I activity may promote inflammatory demyelination still remains to be elucidated, its role in MS in light of the present findings should be further investigated.

Apart from STAT6, there are several other transcription factors that were previously shown to be elevated in MS patients and are controlled by SHP-1. In particular, tyrosine phosphorylated STAT1 (pY-STAT1) that mediates interferon signaling was found to be elevated in MS patients and controlled by SHP-1. ${ }^{20-22,30,58}$ In agreement with those studies, we found that STAT1 activation is enhanced in macrophages of MS patients following IFN- $\gamma$ stimulation. Furthermore, STAT1-inducible genes such as the chemokine IP-10 and caspase 1 are elevated in macrophages of MS patients consistent with a role for STAT1 in expression of these genes. ${ }^{74-79,96}$ Thus, lower levels of SHP-1 seen in macrophages of MS patients may lead to activation of
STAT1 and STAT1-inducible genes that play a role the pathogenesis of MS.

Furthermore, the transcription factor NF- $\kappa \mathrm{B}$ mediates proinflammatory cytokine signaling and is elevated in MS PBMCs $^{19}$ and macrophages in MS lesions. ${ }^{60,61}$ Thus, it may be important that mice genetically lacking SHP-1 show elevated NF- $\kappa$ B activity and increased NF- $\kappa$ B-inducible genes in both CNS glia and hematopoietic cells. ${ }^{9,26,27,59,94}$ Therefore, it was imperative to investigate whether NF- $\kappa \mathrm{B}$-responsive genes were elevated in macrophages of MS patients. Both the chemokine MCP-1 and COX-2 showed significantly elevated induction in macrophages from MS patients compared to normal subjects reflecting the increased NF- $\kappa \mathrm{B}$ binding activity observed in MS macrophages. In addition, the inflammatory cytokines TNF- $\alpha$ and IL-6, which are regulated by NF- $\kappa \mathrm{B}$, were secreted at higher levels in macrophages of MS patients compared to macrophages of normal subjects following LPS or dsRNA stimulation which signal via TLR4 and TLR3, respectively, to activate NF- $\kappa$ B.

Considering that SHP-1-depleted macrophages of normal subjects display a very similar inflammatory profile to macrophages of MS patients, it is likely that the deficiency of SHP-1 seen in macrophages of MS patients is directly responsible for the increased inflammatory profile. As such, the classification of macrophage phenotypic markers may be an important consideration in MS. Several reports in mouse models point to the importance of different macrophage activation profiles in specific types of inflammatory disease. ${ }^{84}$ For instance, so-called classically activated or M1 macrophages display increased STAT1- and NF- $\kappa$ B-responsive genes, which have been shown to be critical for eradicating various intracellular microbes and causing some types of autoaggressive tissue inflammation such as rheumatoid arthritis. Conversely, so-called 'alternatively activated' or M2 macrophages display increased STAT6-responsive genes including arginase I and may be more important for eradicating helminthes and promoting allergic-type inflammatory diseases. Importantly, there is usually a profound antagonism between differentiation toward either M1 or M2 macrophage activation profiles such that dual expression of M1 and M2 genes are rarely seen. In possible distinction to these earlier classifications, this study indicates that macrophages of MS patients may exhibit abnormally high activation of STAT6,

Figure 8 SHP-1 was depleted in macrophages of normal subjects using siRNA and the inflammatory profile in the context of SHP-1 deficiency was characterized. (a) Macrophages of normal subjects were treated with SHP-1 siRNA or control siRNA (scramble sequences) and the levels of SHP-1, arginase I, and actin protein levels were quantified by western immonoblot analysis. In the same panel the amount of SHP-1 and arginase protein measured by western immunoblot were quantified by measuring the pixel density. Results were normalized to macrophages treated with scramble siRNA represented as 1. (b and c) Phosphorylated STAT6 (pSTAT6) and STAT1 (pSTAT1) were quantified by intracellular flow cytometry in normal subject macrophages that were treated with either SHP-1 siRNA or control siRNA. pSTAT6 and PSTAT1 were also quantified following $1 \mathrm{~h}$ treatment with IL-4 or IFN- $\gamma$, respectively. (d-f) Macrophages of normal subjects were pretreated with SHP-1 siRNA or control siRNA and then treated with IL-4, LPS, IFN- $\gamma$, or TNF- $\alpha$ for $18 \mathrm{~h}$. The mRNA levels of CCL17/TARC, CXCL10/IP-10, and CCL2/MCP-1 were quantified by real-time RT-PCR. (h and i) TNF- $\alpha$ and IL-6 secretion was quantified in macrophages of normal subjects that were pretreated with SHP-1 siRNA or control siRNA. Macrophages were cultured in media alone or in the presence of the TLR ligands, LPS, and dsRNA for $18 \mathrm{~h}$ and supernatants were analyzed for TNF- $\alpha$ or IL- 6 by ELISA. (g) The levels of nitrite, as a indicator of nitric oxide (NO) production, were quantified in the supernatants of macrophages from normal subjects that were pretreated with SHP-1 siRNA or control siRNA macrophages following treatment with TNF- $\alpha$ or LPS. 
STAT1, or NF- $\kappa$ B, depending on the nature of cytokine stimulation. As such, a deficiency in SHP-1 may allow an aberrant coactivation of STAT6/STAT1/NF- $\kappa$ B-responsive genes in MS macrophages especially in vivo where these cells may be simultaneously exposed to both M1- and M2-skewing cytokines. If so, the inflammatory nature of these macrophages may be unique and perhaps possess a corresponding enhanced demyelinating capacity.

Such a concurrent activation of normally opposed pathways in MS macrophages is supported by observations of patterns of gene expression in leukocytes including macrophages in MS, where increased coexpression of STAT6/ STAT1/NF- $\kappa$ B-responsive genes is observed. ${ }^{20,21,24,25}$ Adding to the promotion of broad activation phenotype of macrophages in MS are reports showing that high levels of both Th1 and Th2 cytokines are coexpressed in MS. For instance, cultured myeloid dendritic cells from RR MS patients polarize naive T-cells to both Th1 and Th2 and induce increased levels of IFN- $\gamma$, IL-4/IL13, and TNF- $\alpha .{ }^{97,98}$ In accord with these findings, several studies demonstrate that plasma, leukocytes, and CSF of patients with active MS show a concurrent increase of IFN- $\gamma$, IL-4/IL13, and TNF- $\alpha$ levels compared to normal subjects. ${ }^{99-107}$

The high levels of plasma cytokines certainly contributes to the enhanced transcription factor activation previously observed in freshly isolated peripheral blood cells of MS patients. ${ }^{19,21,22}$ In distinction to these earlier studies, this study exclusively employs cultured macrophages of MS patients and normal subjects, which offers the advantage of allowing stimulation of the cells with equal amounts of the cytokines IFN- $\gamma$, IL-4, and TNF- $\alpha$ and, therefore, examining intrinsic differences in cytokine signaling. Therefore, apart from the elevated cytokine levels that are observed in MS patients, this study further documents that macrophages of MS patients display enhanced signaling in response to both Th1 and Th2 proinflammatory cytokines and therefore the lack of SHP-1 may be responsible for a broad inflammatory profile of these cells.

Another question that arises is how the SHP-1 deficiency observed in peripheral macrophages of MS patients might only be manifested as CNS inflammatory demyelination in MS patients. One possibility is that persistent CNS viruses might attract macrophages into the CNS and the lower levels of SHP-1 in MS macrophages enhance migration to and demyelinating activity within the CNS. The latter is supported by studies showing that TMEV infection in SHP-1deficient mice results in severe CNS demyelination that is exclusively macrophage mediated. ${ }^{108}$ Furthermore, deficiency of SHP-1 in macrophages enhances responsiveness to chemokines including MCP-1 that play an important role in macrophage-mediated demyelination. ${ }^{9,51}$ Another possibility is that macrophages are attracted into the CNS through myelin-specific autoimmune events. Once macrophages enter the CNS, the SHP-1-deficiency can contribute to enhanced $\mathrm{Fc}-\gamma$ receptor-mediated myelin phagocytosis in the presence of antibodies and complement. ${ }^{12,109-111}$ These hypotheses indicate a two-step process in which SHP-1-deficiency in macrophages is a precondition to tissue-specific inflammation triggered by a CNS-specific inflammatory signal. The latter is consistent with a recent mouse study in which SHP-1 deficiency alone does not result in inflammatory disease but rather establishes a permissive state in which microbial infection triggers inflammation and autoimmunity. ${ }^{28}$

Two distinct promoters drive the expression of two different SHP-1 transcripts from the SHP-1 gene. ${ }^{112-114}$ Here, we demonstrated that promoter II transcripts, which are preferentially expressed in hematopoietic cells, are selectively lower in macrophages of MS patients compared to normal subjects. The question thus arises as to the potential genetic basis for deficient SHP-1 promoter II activity in MS leukocytes. Several studies have examined the contribution of genetics in $\mathrm{MS}^{115-118}$ and with exception to some weak association in some populations, no study has shown an absolute linkage to the SHP-1 locus, chromosome $12 \mathrm{p} 12^{119}$ that would explain a wide-spread deficiency in promoter II expression in MS patients. As such, alternative mechanisms need to be considered including epigenetic alterations in promoter activity. Indeed, numerous reports document the downregulation of SHP-1 promoter II transcripts in leukemia/lymphoma cell lines and attribute SHP-1 deficiency to epigenetic methylation of particular CpG sites of SHP-1 promoter II. ${ }^{120,121}$ Interestingly, in the context of MS, either viral infections ${ }^{122-127}$ or inflammation ${ }^{128-131}$ can cause de novo methylation or hypermethylate $\mathrm{CpG}$ promoter sequences resulting in decreased gene expression. Furthermore, recent studies report that HTLV-1, which has been associated with the CNS demyelinating disease known as HAM/TSP (HTLV-1 associated myelopathy/Tropical Spastic Parparesis) ${ }^{132}$ profoundly and specifically suppresses SHP-1 expression through methylation of the SHP-1 promoter II. ${ }^{133,134}$ In accordance with these reports, preliminary data indicate that treatment of PBMCs of MS patients with the demethylating agent 2'-deoxy-5-azacytidine increase SHP-1 promoter II transcripts to normal levels (personal unpublished observations). Whether a stable epigenetic modification of promoter II or another mechanism results in a deficiency in SHP-1 expression in macrophages from MS patients requires further investigation.

\section{ACKNOWLEDGEMENTS}

We thank Dr Isobel Scarisbrick at Mayo Clinic for providing cDNA plamids used in performing real-time RT-PCR. We thank Carol Ozark for collection of normal subject blood samples. We also thank Dr Nick J Gonchoroff, for his expertise in flow cytometry/cell sorting performed in this study.

1. Noseworthy JH, Lucchinetti C, Rodriguez $\mathrm{M}$, et al. Multiple sclerosis. N Engl J Med 2000;343:938-952.

2. Lucchinetti C, Bruck W, Parisi J, et al. Heterogeneity of multiple sclerosis lesions: implications for the pathogenesis of demyelination. Ann Neurol 2000;47:707-717.

3. Kornek B, Lassmann H. Neuropathology of multiple sclerosis-new concepts. Brain Res Bull 2003;61:321-326. 
4. Bruck W, Sommermeier N, Bergmann $M$, et al. Macrophages in multiple sclerosis. Immunobiology 1996;195:588-600.

5. Trebst C, Sorensen TL, Kivisakk $P$, et al. CCR1+/CCR5+ mononuclear phagocytes accumulate in the central nervous system of patients with multiple sclerosis. Am J Pathol 2001;159:1701-1710.

6. Lipton $\mathrm{HL}$, Kumar AS, Trottier M. Theiler's virus persistence in the central nervous system of mice is associated with continuous viral replication and a difference in outcome of infection of infiltrating macrophages versus oligodendrocytes. Virus Res 2005;111:214-223.

7. Hendriks JJ, Teunissen $\mathrm{CE}$, de Vries $\mathrm{HE}$, et al. Macrophages and neurodegeneration. Brain Res Brain Res Rev 2005;48:185-195.

8. Benveniste EN. Role of macrophages/microglia in multiple sclerosis and experimental allergic encephalomyelitis. J Mol Med 1997:75:165-173.

9. Christophi GP, Hudson CA, Panos M, et al. Modulation of macrophage infiltration and inflammatory activity by the phosphatase SHP-1 in virus-induced demyelinating disease. J Virol 2009;83:522-539.

10. Templeton SP, Kim TS, O'Malley K, et al. Maturation and localization of macrophages and microglia during infection with a neurotropic murine coronavirus. Brain Pathol 2008;18:40-51.

11. Hiremath MM, Saito $Y$, Knapp GW, et al. Microglial/macrophage accumulation during cuprizone-induced demyelination in $\mathrm{C} 57 \mathrm{BL} / 6$ mice. J Neuroimmunol 1998;92:38-49.

12. Breij EC, Brink BP, Veerhuis R, et al. Homogeneity of active demyelinating lesions in established multiple sclerosis. Ann Neurol 2008;63:16-25.

13. Dogan RN, Karpus WJ. Chemokines and chemokine receptors in autoimmune encephalomyelitis as a model for central nervous system inflammatory disease regulation. Front Biosci 2004;9: 1500-1505.

14. Ubogu EE, Cossoy MB, Ransohoff RM. The expression and function of chemokines involved in CNS inflammation. Trends Pharmacol Sci 2006;27:48-55.

15. Rodriguez M. Effectors of demyelination and remyelination in the CNS: implications for multiple sclerosis. Brain Pathol 2007;17:219-229.

16. Scarisbrick IA, Linbo $R$, Vandell $A G$, et al. Kallikreins are associated with secondary progressive multiple sclerosis and promote neurodegeneration. Biol Chem 2008;389:739-745.

17. Scarisbrick IA, Blaber SI, Lucchinetti CF, et al. Activity of a newly identified serine protease in CNS demyelination. Brain 2002;125(Part 6):1283-1296.

18. Karpus WJ, Kennedy KJ, Fife BT, et al. Anti-CCL2 treatment inhibits Theiler's murine encephalomyelitis virus-induced demyelinating disease. J Neurovirol 2006;12:251-261.

19. Eggert M, Goertsches $R$, Seeck U, et al. Changes in the activation leve of NF-kappa B in lymphocytes of MS patients during glucocorticoid pulse therapy. J Neurol Sci 2008;264:145-150.

20. Gobin SJ, Montagne L, Van Zutphen M, et al. Upregulation of transcription factors controlling $\mathrm{MHC}$ expression in multiple sclerosis lesions. Glia 2001;36:68-77.

21. Frisullo G, Angelucci F, Caggiula $M$, et al. pSTAT1, pSTAT3, and T-bet expression in peripheral blood mononuclear cells from relapsingremitting multiple sclerosis patients correlates with disease activity. J Neurosci Res 2006;84:1027-1036.

22. Feng $X$, Petraglia $A L, C$ hen $M$, et al. Low expression of interferonstimulated genes in active multiple sclerosis is linked to subnormal phosphorylation of STAT1. J Neuroimmunol 2002;129:205-215.

23. Zeis T, Graumann U, Reynolds $\mathrm{R}$, et al. Normal-appearing white matter in multiple sclerosis is in a subtle balance between inflammation and neuroprotection. Brain 2008;131(Part 1):288-303.

24. Cannella B, Raine CS. Multiple sclerosis: cytokine receptors on oligodendrocytes predict innate regulation. Ann Neurol 2004;55 :46-57.

25. Christophi GP, Hudson CA, Gruber RC, et al. SHP-1 deficiency and increased inflammatory gene expression in PBMCs of multiple sclerosis patients. Lab Invest 2008;88:243-255.

26. Massa PT, Wu C. Increased inducible activation of NF-kappaB and responsive genes in astrocytes deficient in the protein tyrosine phosphatase SHP-1. J Interferon Cytokine Res 1998;18:499-507.

27. Khaled AR, Butfiloski EJ, Sobel ES, et al. Functional consequences of the SHP-1 defect in motheaten viable mice: role of NF-kappa B. Cell Immunol 1998;185:49-58.
28. Croker BA, Lawson BR, Berger $\mathrm{M}$, et al. Inflammation and autoimmunity caused by a SHP1 mutation depend on IL-1, MyD88, and a microbial trigger. Proc Natl Acad Sci USA 2008;105:15028-15033.

29. David M, Chen HE, Goelz S, et al. Differential regulation of the alpha/ beta interferon-stimulated Jak/Stat pathway by the $\mathrm{SH} 2$ domaincontaining tyrosine phosphatase SHPTP1. Mol Cell Biol 1995;15: 7050-7058.

30. Massa PT, Wu C. The role of protein tyrosine phosphatase SHP-1 in the regulation of IFN-gamma signaling in neural cells. J Immunol 1996:157:5139-5144.

31. Bonaparte $\mathrm{KL}$, Hudson $\mathrm{CA}, \mathrm{Wu} \mathrm{C}$, et al. Inverse regulation of inducible nitric oxide synthase (iNOS) and arginase I by the protein tyrosine phosphatase SHP-1 in CNS glia. Glia 2006;53:827-835.

32. Hanson EM, Dickensheets $\mathrm{H}, \mathrm{Qu} C K$, et al. Regulation of the dephosphorylation of Stat6. Participation of Tyr-713 in the interleukin-4 receptor alpha, the tyrosine phosphatase SHP-1, and the proteasome. J Biol Chem 2003;278:3903-3911.

33. Huang $\mathrm{Z}$, Coleman JM, Su Y, et al. SHP-1 regulates STAT6 phosphorylation and IL-4-mediated function in a cell type-specific manner. Cytokine 2005;29:118-124.

34. Kamata T, Yamashita M, Kimura $M$, et al. src homology 2 domaincontaining tyrosine phosphatase SHP-1 controls the development of allergic airway inflammation. J Clin Invest 2003;111:109-119.

35. Massa PT, Saha $S, W u ~ C$, et al. Expression and function of the protein tyrosine phosphatase SHP-1 in oligodendrocytes. Glia 2000;29:376-385.

36. Massa PT, Wu C, Fecenko-Tacka K. Dysmyelination and reduced myelin basic protein gene expression by oligodendrocytes of SHP-1deficient mice. J Neurosci Res 2004;77:15-25.

37. Massa PT, Ropka SL, Saha S, et al. Critical role for protein tyrosine phosphatase SHP-1 in controlling infection of central nervous system glia and demyelination by Theiler's murine encephalomyelitis virus. J Virol 2002;76:8335-8346.

38. Deng C, Minguela A, Hussain RZ, et al. Expression of the tyrosine phosphatase SRC homology 2 domain-containing protein tyrosine phosphatase 1 determines $\mathrm{T}$ cell activation threshold and severity of experimental autoimmune encephalomyelitis. J Immunol 2002; 168:4511-4518.

39. Wasserman HA, Beal CD, Zhang $Y$, et al. MHC variant peptidemediated anergy of encephalitogenic $T$ cells requires SHP-1. J Immunol 2008;181:6843-6849.

40. McDonald WI, Compston A, Edan G, et al. Recommended diagnostic criteria for multiple sclerosis: guidelines from the International Panel on the diagnosis of multiple sclerosis. Ann Neurol 2001;50: 121-127.

41. De Nichilo MO, Burns GF. Granulocyte-macrophage and macrophage colony-stimulating factors differentially regulate alpha $v$ integrin expression on cultured human macrophages. Proc Natl Acad Sci USA 1993;90:2517-2521.

42. Blystone SD, Graham IL, Lindberg FP, et al. Integrin alpha v beta 3 differentially regulates adhesive and phagocytic functions of the fibronectin receptor alpha 5 beta 1. J Cell Biol 1994;127:1129-1137.

43. Christophi GP, Hudson CA, Gruber R, et al. Promoter-specific induction of the phosphatase SHP-1 by viral infection and cytokines in CNS glia. J Neurochem 2008;105:2511-2523.

44. Krissansen GW, Elliott MJ, Lucas CM, et al. Identification of a novel integrin beta subunit expressed on cultured monocytes (macrophages). Evidence that one alpha subunit can associate with multiple beta subunits. J Biol Chem 1990;265:823-830.

45. Christophi GP, Isackson PJ, Blaber S, et al. Distinct promoters regulate tissue-specific and differential expression of kallikrein 6 in CNS demyelinating disease. J Neurochem 2004;91:1439-1449.

46. Renard P, Ernest I, Houbion A, et al. Development of a sensitive multiwell colorimetric assay for active NFkappaB. Nucleic Acids Res 2001;29:E21.

47. Zhu L, Zou W, Yu C, et al. Human recombinant PLD2 can repress p65 activity of guinea pigs of chronic asthma in vivo. Cell Mol Immunol 2006;3:307-310.

48. Sun J, Ramnath RD, Tamizhselvi R, et al. Neurokinin A engages neurokinin-1 receptor to induce NF-kappaB-dependent gene expression in murine macrophages: implications of ERK1/2 and $\mathrm{PI}$ 3-kinase/Akt pathways. Am J Physiol Cell Physiol 2008;295: c679-C691. 
49. Hudson CA, Christophi GP, Gruber RC, et al. Induction of IL-33 expression and activity in central nervous system glia. J Leukoc Biol 2008:84:631-643.

50. Imhof BA, Aurrand-Lions M. Adhesion mechanisms regulating the migration of monocytes. Nat Rev Immunol 2004;4:432-444.

51. Kim CH, Qu CK, Hangoc $\mathrm{G}$, et al. Abnormal chemokine-induced responses of immature and mature hematopoietic cells from motheaten mice implicate the protein tyrosine phosphatase SHP-1 in chemokine responses. J Exp Med 1999;190:681-690.

52. Forget G, Matte $C$, Siminovitch KA, et al. Regulation of the Leishmania-induced innate inflammatory response by the protein tyrosine phosphatase SHP-1. Eur J Immunol 2005;35:1906-1917.

53. Mazzone A, Ricevuti G. Leukocyte CD11/CD18 integrins: biological and clinical relevance. Haematologica 1995;80:161-175.

54. Meerschaert J, Furie MB. The adhesion molecules used by monocytes for migration across endothelium include CD11a/CD18, CD11b/CD18, and VLA-4 on monocytes and ICAM-1, VCAM-1, and other ligands on endothelium. J Immunol 1995;154:4099-4112.

55. Mazzone A, De Servi S, Mazzucchelli I, et al. Increased expression of CD11b/CD18 on phagocytes in ischaemic disease: a bridge between inflammation and coagulation. Eur J Clin Invest 1997;27:648-652.

56. Rice GP, Hartung HP, Calabresi PA. Anti-alpha4 integrin therapy for multiple sclerosis: mechanisms and rationale. Neurology 2005; 64:1336-1342.

57. Haque SJ, Harbor P, Tabrizi M, et al. Protein-tyrosine phosphatase Shp-1 is a negative regulator of IL-4- and IL-13-dependent signal transduction. J Biol Chem 1998;273:33893-33896.

58. Yetter A, Uddin S, Krolewski JJ, et al. Association of the interferondependent tyrosine kinase Tyk-2 with the hematopoietic cell phosphatase. J Biol Chem 1995;270:18179-18182.

59. Zhang Z, Jimi E, Bothwell AL. Receptor activator of NF-kappa B ligand stimulates recruitment of SHP-1 to the complex containing TNFRassociated factor 6 that regulates osteoclastogenesis. J Immunol 2003;171:3620-3626.

60. Bonetti B, Stegagno C, Cannella B, et al. Activation of NF-kappaB and c-jun transcription factors in multiple sclerosis lesions. Implications for oligodendrocyte pathology. Am J Pathol 1999;155:1433-1438.

61. Gveric D, Kaltschmidt C, Cuzner ML, et al. Transcription factor NFkappaB and inhibitor I kappaBalpha are localized in macrophages in active multiple sclerosis lesions. J Neuropathol Exp Neurol 1998; 57:168-178.

62. Zhao J, Brooks DM, Lurie DI. Lipopolysaccharide-activated SHP-1deficient motheaten microglia release increased nitric oxide, TNFalpha, and IL-1beta. Glia 2006;53:304-312.

63. Wu L, Iwai M, Li Z, et al. Regulation of inhibitory protein-kappaB and monocyte chemoattractant protein-1 by angiotensin II type 2 receptor-activated Src homology protein tyrosine phosphatase-1 in fetal vascular smooth muscle cells. Mol Endocrinol 2004:18:666-678.

64. Thrall RS, Vogel SN, Evans R, et al. Role of tumor necrosis factor-alpha in the spontaneous development of pulmonary fibrosis in viable motheaten mutant mice. Am J Pathol 1997;151:1303-1310.

65. An H, Hou J, Zhou J, et al. Phosphatase SHP-1 promotes TLR- and RIGI-activated production of type I interferon by inhibiting the kinase IRAK1. Nat Immunol 2008;9:542-550.

66. Hudson CA, Christophi GP, Cao L, et al. Regulation of avoidant behaviors and pain by the anti-inflammatory tyrosine phosphatase SHP-1. Neuron Glia Biol 2006:2:235-246.

67. Wirnsberger G, Hebenstreit D, Posselt G, et al. IL-4 induces expression of TARC/CCL17 via two STAT6 binding sites. Eur J Immunol 2006;36:1882-1891.

68. Narikawa K, Misu T, Fujihara K, et al. CSF chemokine levels in relapsing neuromyelitis optica and multiple sclerosis. J Neuroimmunol 2004:149:182-186.

69. Matsukura S, Stellato C, Georas SN, et al. Interleukin-13 upregulates eotaxin expression in airway epithelial cells by a STAT6-dependent mechanism. Am J Respir Cell Mol Biol 2001;24:755-761.

70. Richens J, Fairclough L, Ghaemmaghami AM, et al. The detection of ADAM8 protein on cells of the human immune system and the demonstration of its expression on peripheral blood B cells, dendritic cells and monocyte subsets. Immunobiology 2007;212:29-38.

71. King NE, Zimmermann N, Pope SM, et al. Expression and regulation of a disintegrin and metalloproteinase (ADAM) 8 in experimental asthma. Am J Respir Cell Mol Biol 2004;31:257-265.
72. Amour A, Knight CG, English WR, et al. The enzymatic activity of ADAM8 and ADAM9 is not regulated by TIMPs. FEBS Lett 2002:524:154-158.

73. $\mathrm{Xu}$ L, Hilliard B, Carmody RJ, et al. Arginase and autoimmune inflammation in the central nervous system. Immunology 2003; 110:141-148.

74. Sorensen $\mathrm{TL}$, Tani M, Jensen J, et al. Expression of specific chemokines and chemokine receptors in the central nervous system of multiple sclerosis patients. J Clin Invest 1999;103:807-815.

75. Simpson JE, Newcombe J, Cuzner ML, et al. Expression of the interferon-gamma-inducible chemokines IP-10 and Mig and their receptor, CXCR3, in multiple sclerosis lesions. Neuropathol Appl Neurobiol 2000;26:133-142.

76. Salmaggi A, Gelati $M$, Dufour A, et al. Expression and modulation of IFN-gamma-inducible chemokines (IP-10, Mig, and I-TAC) in human brain endothelium and astrocytes: possible relevance for the immune invasion of the central nervous system and the pathogenesis of multiple sclerosis. J Interferon Cytokine Res 2002;22:631-640.

77. Tanuma N, Sakuma H, Sasaki A, et al. Chemokine expression by astrocytes plays a role in microglia/macrophage activation and subsequent neurodegeneration in secondary progressive multiple sclerosis. Acta Neuropathol 2006;112:195-204.

78. Omari KM, John GR, Sealfon SC, et al. CXC chemokine receptors on human oligodendrocytes: implications for multiple sclerosis. Brain 2005;128(Part 5):1003-1015.

79. Huang WX, Huang P, Hillert J. Increased expression of caspase-1 and interleukin-18 in peripheral blood mononuclear cells in patients with multiple sclerosis. Mult Scler 2004;10:482-487.

80. Chin YE, Kitagawa M, Kuida K, et al. Activation of the STAT signaling pathway can cause expression of caspase 1 and apoptosis. Mol Cell Biol 1997;17:5328-5337.

81. Furlan R, Martino G, Galbiati F, et al. Caspase-1 regulates the inflammatory process leading to autoimmune demyelination. J Immunol 1999;163:2403-2409.

82. Ahn KS, Aggarwal BB. Transcription factor NF-kappaB: a sensor for smoke and stress signals. Ann NY Acad Sci 2005;1056:218-233.

83. Quinones MP, Kalkonde $Y$, Estrada CA, et al. Role of astrocytes and chemokine systems in acute TNFalpha induced demyelinating syndrome: CCR2-dependent signals promote astrocyte activation and survival via NF-kappaB and Akt. Mol Cell Neurosci 2008;37:96-109.

84. Benoit M, Desnues B, Mege JL. Macrophage polarization in bacterial infections. J Immunol 2008;181:3733-3739.

85. Nguyen VT, Benveniste EN. IL-4-activated STAT-6 inhibits IFN-gammainduced CD40 gene expression in macrophages/microglia. J Immunol 2000;165:6235-6243.

86. Hamilton TA, Ohmori Y, Tebo JM, et al. Regulation of macrophage gene expression by pro- and anti-inflammatory cytokines. Pathobiology 1999;67:241-244.

87. Major J, Fletcher JE, Hamilton TA. IL-4 pretreatment selectively enhances cytokine and chemokine production in lipopolysaccharidestimulated mouse peritoneal macrophages. J Immunol 2002;168: 2456-2463.

88. Hesse $M$, Modolell $M$, La Flamme AC, et al. Differential regulation of nitric oxide synthase- 2 and arginase- 1 by type 1/type 2 cytokines in vivo: granulomatous pathology is shaped by the pattern of L-arginine metabolism. J Immunol 2001;167:6533-6544.

89. Bruck W, Porada P, Poser S, et al. Monocyte/macrophage differentiation in early multiple sclerosis lesions. Ann Neurol 1995;38:788-796.

90. van der Goes A, Boorsma W, Hoekstra K, et al. Determination of the sequential degradation of myelin proteins by macrophages. J Neuroimmunol 2005;161:12-20.

91. Raivich G, Banati R. Brain microglia and blood-derived macrophages: molecular profiles and functional roles in multiple sclerosis and animal models of autoimmune demyelinating disease. Brain Res Brain Res Rev 2004;46:261-281.

92. Belperio JA, Dy M, Murray L, et al. The role of the Th2 CC chemokine ligand CCL17 in pulmonary fibrosis. J Immunol 2004;173: 4692-4698.

93. Wenzel J, Henze S, Worenkamper E, et al. Role of the chemokine receptor CCR4 and its ligand thymus- and activation-regulated chemokine/CCL17 for lymphocyte recruitment in cutaneous lupus erythematosus. J Invest Dermatol 2005;124:1241-1248. 
94. Menzies-Gow A, Ying S, Sabroe I, et al. Eotaxin (CCL11) and eotaxin-2 (CCL24) induce recruitment of eosinophils, basophils, neutrophils, and macrophages as well as features of early- and late-phase allergic reactions following cutaneous injection in human atopic and nonatopic volunteers. J Immunol 2002;169:2712-2718.

95. Scarisbrick IA. The multiple sclerosis degradome: enzymatic cascades in development and progression of central nervous system inflammatory disease. Curr Top Microbiol Immunol 2008;318: $133-175$.

96. Ming X, Li W, Maeda $Y$, et al. Caspase-1 expression in multiple sclerosis plaques and cultured glial cells. J Neurol Sci 2002;197:9-18.

97. Karni A, Abraham M, Monsonego A, et al. Innate immunity in multiple sclerosis: myeloid dendritic cells in secondary progressive multiple sclerosis are activated and drive a proinflammatory immune response. J Immunol 2006;177:4196-4202.

98. Huang YM, Xiao BG, Ozenci V, et al. Multiple sclerosis is associated with high levels of circulating dendritic cells secreting proinflammatory cytokines. J Neuroimmunol 1999:99:82-90.

99. Link J, Soderstrom M, Olsson $\mathrm{T}$, et al. Increased transforming growth factor-beta, interleukin-4, and interferon-gamma in multiple sclerosis. Ann Neurol 1994;36:379-386.

100. Link H. The cytokine storm in multiple sclerosis. Mult Scler 1998; 4:12-15.

101. Hermans $G$, Stinissen $P$, Hauben $L$, et al. Cytokine profile of myelin basic protein-reactive $T$ cells in multiple sclerosis and healthy individuals. Ann Neurol 1997;42:18-27.

102. Rohowsky-Kochan C, Molinaro D, Cook SD. Cytokine secretion profile of myelin basic protein-specific T cells in multiple sclerosis. Mult Scler 2000;6:69-77.

103. Ochi $\mathrm{H}$, Osoegawa $\mathrm{M}, \mathrm{Wu} \mathrm{XM}$, et al. Increased IL-13 but not IL-5 production by CD4-positive $T$ cells and CD8-positive $T$ cells in multiple sclerosis during relapse phase. J Neurol Sci 2002;201: 45-51.

104. Ozenci V, Kouwenhoven M, Huang YM, et al. Multiple sclerosis is associated with an imbalance between tumour necrosis factor-alpha (TNF-alpha)- and IL-10-secreting blood cells that is corrected by interferon-beta (IFN-beta) treatment. Clin Exp Immunol 2000;120:147-153.

105. Hohnoki K, Inoue A, Koh CS. Elevated serum levels of IFN-gamma, IL-4 and TNF-alpha/unelevated serum levels of IL-10 in patients with demyelinating diseases during the acute stage. J Neuroimmunol 1998;87:27-32.

106. Ishizu T, Osoegawa M, Mei FJ, et al. Intrathecal activation of the IL-17/ IL-8 axis in opticospinal multiple sclerosis. Brain 2005;128(Part 5): 988-1002.

107. Killestein J, Den Drijver BF, Van der Graaff WL, et al. Intracellular cytokine profile in T-cell subsets of multiple sclerosis patients: different features in primary progressive disease. Mult Scler 2001;7:145-150.

108. Christophi GP, Hudson CA, Panos M, et al. Modulation of macrophage infiltration and inflammatory activity by the phosphatase SHP-1 in virus-induced demyelinating disease. J Virol 2009;83:522-539.

109. Kant AM, De P, Peng $X$, et al. SHP-1 regulates Fcgamma receptormediated phagocytosis and the activation of RAC. Blood 2002:100:1852-1859.

110. Oldenborg PA, Gresham HD, Lindberg FP. CD47-signal regulatory protein alpha (SIRPalpha) regulates Fcgamma and complement receptor-mediated phagocytosis. J Exp Med 2001;193:855-862.

111. Huang ZY, Hunter S, Kim MK, et al. The effect of phosphatases SHP-1 and SHIP-1 on signaling by the ITIM- and ITAM-containing Fcgamma receptors FcgammaRIIB and FcgammaRIIA. J Leukoc Biol 2003;73:823-829.

112. Banville D, Stocco R, Shen SH. Human protein tyrosine phosphatase 1C (PTPN6) gene structure: alternate promoter usage and exon skipping generate multiple transcripts. Genomics 1995;27:165-173.

113. Tsui HW, Hasselblatt K, Martin A, et al. Molecular mechanisms underlying SHP-1 gene expression. Eur J Biochem 2002;269: 3057-3064.
114. Xu Y, Banville D, Zhao HF, et al. Transcriptional activity of the SHP-1 gene in MCF7 cells is differentially regulated by binding of NF-Y factor to two distinct CCAAT-elements. Gene 2001;269:141-153.

115. Oksenberg JR, Barcellos LF. Multiple sclerosis genetics: leaving no stone unturned. Genes Immun 2005;6:375-387.

116. Hafler DA, Compston A, Sawcer S, et al. Risk alleles for multiple sclerosis identified by a genomewide study. N Engl J Med 2007:357:851-862.

117. Karpuj MV, Steinman L, Oksenberg JR. Multiple sclerosis: a polygenic disease involving epistatic interactions, germline rearrangements and environmental effects. Neurogenetics 1997;1:21-28.

118. Asimakopoulos FA, Hinshelwood S, Gilbert JG, et al. The gene encoding hematopoietic cell phosphatase (SHP-1) is structurally and transcriptionally intact in polycythemia vera. Oncogene 1997; 14:1215-1222.

119. Yi TL, Cleveland JL, Ihle JN. Protein tyrosine phosphatase containing SH2 domains: characterization, preferential expression in hematopoietic cells, and localization to human chromosome 12p12-p13. Mol Cell Biol 1992;12:836-846.

120. Zhang Q, Raghunath PN, Vonderheid E, et al. Lack of phosphotyrosine phosphatase SHP-1 expression in malignant T-cell lymphoma cells results from methylation of the SHP-1 promoter. Am J Pathol 2000;157:1137-1146.

121. Oka T, Yoshino $T$, Hayashi $K$, et al. Reduction of hematopoietic cellspecific tyrosine phosphatase SHP-1 gene expression in natural killer cell lymphoma and various types of lymphomas/leukemias: combination analysis with CDNA expression array and tissue microarray. Am J Pathol 2001;159:1495-1505.

122. Osawa $T$, Chong JM, Sudo $M$, et al. Reduced expression and promoter methylation of p16 gene in Epstein-Barr virus-associated gastric carcinoma. Jpn J Cancer Res 2002;93:1195-1200.

123. Muller K, Heller H, Doerfler W. Foreign DNA integration. Genomewide perturbations of methylation and transcription in the recipient genomes. J Biol Chem 2001;276:14271-14278.

124. de Bustros A, Nelkin BD, Silverman A, et al. The short arm of chromosome 11 is a 'hot spot' for hypermethylation in human neoplasia. Proc Natl Acad Sci USA 1988;85:5693-5697.

125. Mikovits JA, Young HA, Vertino $P$, et al. Infection with human immunodeficiency virus type 1 upregulates DNA methyltransferase, resulting in de novo methylation of the gamma interferon (IFNgamma) promoter and subsequent downregulation of IFN-gamma production. Mol Cell Biol 1998;18:5166-5177.

126. Amara $K$, Trimeche $M$, Ziadi $S$, et al. Presence of simian virus 40 DNA sequences in diffuse large B-cell lymphomas in Tunisia correlates with aberrant promoter hypermethylation of multiple tumor suppressor genes. Int J Cancer 2007;121:2693-2702.

127. Lipton HL, Liang Z, Hertzler S, et al. A specific viral cause of multiple sclerosis: one virus, one disease. Ann Neurol 2007;61:514-523.

128. Valinluck V, Sowers LC. Inflammation-mediated cytosine damage: a mechanistic link between inflammation and the epigenetic alterations in human cancers. Cancer Res 2007;67:5583-5586.

129. Valinluck V, Sowers LC. Endogenous cytosine damage products alter the site selectivity of human DNA maintenance methyltransferase DNMT1. Cancer Res 2007:67:946-950.

130. Rouleau J, MacLeod AR, Szyf M. Regulation of the DNA methyltransferase by the Ras-AP-1 signaling pathway. J Biol Chem 1995;270:1595-1601.

131. Hmadcha A, Bedoya FJ, Sobrino F, et al. Methylation-dependent gene silencing induced by interleukin 1 beta via nitric oxide production. J Exp Med 1999;190:1595-1604.

132. Araujo $A Q$, Silva MT. The HTLV-1 neurological complex. Lancet Neurol 2006;5:1068-1076.

133. Cheng J, Kydd AR, Nakase $\mathrm{K}$, et al. Negative regulation of the $\mathrm{SH} 2$ homology containing protein-tyrosine phosphatase-1 (SHP-1) P2 promoter by the HTLV-1 Tax oncoprotein. Blood 2007;110:2110-2120.

134. Nakase K, Cheng J, Zhu Q, et al. Mechanisms of SHP-1 P2 promoter regulation in hematopoietic cells and its silencing in HTLV-1transformed T cells. J Leukoc Biol 2009:85:165-174. 